\title{
Model sensitivity studies regarding the role of the retention coefficient for the scavenging and redistribution of highly soluble trace gases by deep convective cloud systems
}

\author{
M. Salzmann ${ }^{1}$, M. G. Lawrence ${ }^{1}$, V. T. J. Phillips ${ }^{2}$, and L. J. Donner ${ }^{2}$ \\ ${ }^{1}$ Max-Planck-Institute for Chemistry, Department of Atmospheric Chemistry, P.O. Box 3060, 55020 Mainz, Germany \\ ${ }^{2}$ Geophysical Fluid Dynamics Laboratory, NOAA, Princeton University, P.O. Box 308, Princeton, NJ 08542, USA
}

Received: 19 September 2006 - Published in Atmos. Chem. Phys. Discuss.: 24 October 2006

Revised: 14 February 2007 - Accepted: 6 April 2007 - Published: 24 April 2007

\begin{abstract}
The role of the retention coefficient (i.e. the fraction of a dissolved trace gas which is retained in hydrometeors during freezing) for the scavenging and redistribution of highly soluble trace gases by deep convective cloud systems is investigated using a modified version of the Weather Research and Forecasting (WRF) model. Results from cloud system resolving model runs (in which deep convection is initiated by small random perturbations in association with so-called "large scale forcings (LSF)") for a tropical oceanic (TOGA COARE) and a mid-latitude continental case (ARM) are compared to two runs in which bubbles are used to initiate deep convection (STERAO, ARM). In the LSF runs, scavenging is found to almost entirely prevent a highly soluble tracer initially located in the lowest $1.5 \mathrm{~km}$ of the troposphere from reaching the upper troposphere, independent of the retention coefficient. The release of gases from freezing hydrometeors leads to mixing ratio increases in the upper troposphere comparable to those calculated for insoluble trace gases only in the two runs in which bubbles are used to initiate deep convection. A comparison of the two ARM runs indicates that using bubbles to initiate deep convection may result in an overestimate of the influence of the retention coefficient on the vertical transport of highly soluble tracers.

It is, however, found that the retention coefficient plays an important role for the scavenging and redistribution of highly soluble trace gases with a (chemical) source in the free troposphere and also for trace gases for which even relatively inefficient transport may be important. The large difference between LSF and bubble runs is attributed to differences in dynamics and microphysics in the inflow regions of the storms. The dependence of the results on the model setup
\end{abstract}

Correspondence to: M. Salzmann

(salzmann@mpch-mainz.mpg.de) indicates the need for additional model studies with a more realistic initiation of deep convection, e.g., considering effects of orography in a nested model setup.

\section{Introduction}

Deep convective clouds can rapidly transport trace gases from the lower to the upper troposphere (e.g. Isaac and Joe, 1983; Chatfield and Crutzen, 1984; Dickerson et al., 1987) where in many cases their chemical lifetimes are longer, and, especially at mid-latitudes, horizontal winds are generally stronger. Highly soluble trace gases, on the other hand, are efficiently scavenged due to uptake in liquid hydrometeors and subsequent removal by precipitation (e.g. Hales and Dana, 1979; Wang and Crutzen, 1995; Crutzen and Lawrence, 2000). A few recent model studies (Crutzen and Lawrence, 2000; Mari et al., 2000; Barth et al., 2001; Yin et al., 2002) have, however, suggested that even highly soluble trace gases can reach the upper troposphere if they are released from freezing hydrometeors at high altitudes. In a cloud resolving model study of a mid-latitude storm, Barth et al. (2001) found that when soluble trace gases were assumed to be released from hydrometeors upon freezing, both low and high solubility tracers were transported to the upper troposphere. When the tracers were assumed to be retained in ice hydrometeors, the highly soluble tracers were not ultimately transported to the upper troposphere, but precipitated out instead. Using an axis-symmetric cloud model with a size-bin-resolving microphysics scheme, Yin et al. (2002) also found the deep convective transport of highly soluble trace gases to depend on the retention coefficient, especially under maritime conditions. Based on results from

Published by Copernicus GmbH on behalf of the European Geosciences Union. 


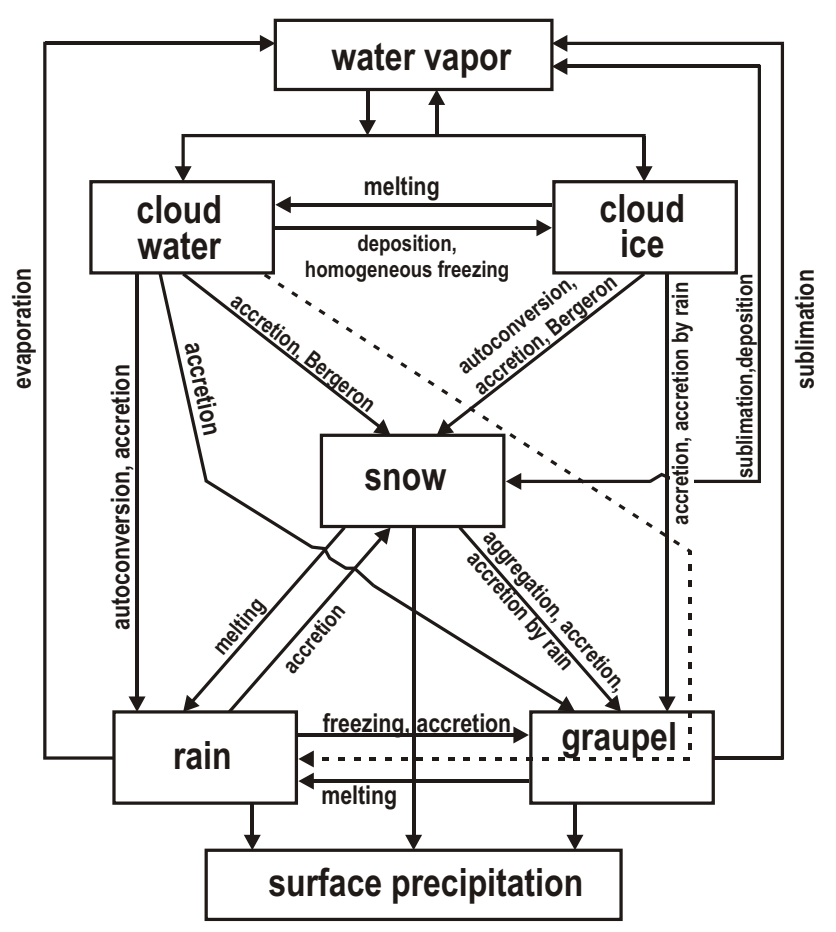

Fig. 1. Schematic: Processes considered in the microphysics parameterization. Adapted from Lin et al. (1983).

a one-dimensional entraining/detraining plume model, Mari et al. (2000) suggested that inefficient scavenging of hydrogen peroxide $\left(\mathrm{H}_{2} \mathrm{O}_{2}\right)$ in glaciated clouds may explain the observations of enhanced $\mathrm{H}_{2} \mathrm{O}_{2}$ in outflow from deep convection. Whether $\mathrm{H}_{2} \mathrm{O}_{2}$ is completely scavenged in deep convection because of its high solubility or whether some $\mathrm{H}_{2} \mathrm{O}_{2}$ is injected into the upper troposphere during hydrometeor freezing could potentially play an important role for the $\mathrm{HO}_{\mathrm{x}}\left(=\mathrm{HO}_{2}+\mathrm{OH}\right)$ budget of the upper troposphere (Chatfield and Crutzen, 1984; Prather and Jacob, 1997; Jaeglé et al., 1997). In the present study, the influence of the retention coefficient on the transport and scavenging of idealized, highly soluble tracers with various initial profiles is investigated. Direct uptake on ice from the gas phase is not considered. The following two sections provide a description of the model and an overview of the meteorological aspects of the simulations. Results for the transport and scavenging of highly soluble tracers with two different initial profiles are presented in Sect. 4. The influences of the simulated cloud dynamics and microphysics on the transport are investigated in Sect. 5. In Sect. 6, the results are discussed in light of observed increases of upper tropospheric $\mathrm{H}_{2} \mathrm{O}_{2}$ mixing ratios in deep convective outflow. In order to reconcile our results with the observations, results from additional sensitivity runs are presented.

\section{Model description}

A modified height coordinate prototype version of the nonhydrostatic, compressible Weather and Research and Forecasting Model (WRF) is used in this study. The WRF model is a community model which is being developed in a collaborative effort by the National Center for Atmospheric Research (NCAR), the National Centers for Environmental Prediction (NCEP), the Air Force Weather Agency, Oklahoma University, and other partners. It was designed as a regional model which is capable of operating at high resolutions. The source code as well as additional information can be obtained from the WRF model web site at http://wrf-model.org. The basic equations can be found in Skamarock et al. (2001) and the numerics are described in Wicker and Skamarock (2002).

In the present study, microphysical processes are parametrized using a single-moment scheme based on Lin et al. (1983) which is different from the one in the WRF model distribution. The scheme is described by Krueger et al. (1995) and is based on a study by Lord et al. (1984). In the scheme a distinction is made between five hydrometeor categories: cloud droplets (cloud water), rain, small ice particles (cloud ice), graupel, and snow. Auto-conversion concepts are used to parametrize collisioncoalescence and collision-aggregation processes. The processes included are: sedimentation of rain, snow, graupel, and cloud ice, evaporation of rain, melting and sublimation of snow and graupel, Bergeron-type processes which convert cloud water and cloud ice into snow, autoconversion of suspended particles into precipitation, and various accretion processes (see the schematic in Fig. 1). The densities for cloud ice, snow, and graupel are set to $\rho_{i}=917 \mathrm{~kg} \mathrm{~m}^{-3}$, $\rho_{s}=100 \mathrm{~kg} \mathrm{~m}^{-3}$, and $\rho_{g}=400 \mathrm{~kg} \mathrm{~m}^{-3}$, respectively. The intercept parameters of the Marshall-Palmer size distributions for rain, snow, and graupel are $n_{0 r}=8 \times 10^{6} \mathrm{~m}^{-4}$, $n_{0 s}=3 \times 10^{6} \mathrm{~m}^{-4}, n_{0 g}=4 \times 10^{6} \mathrm{~m}^{-4}$. The radius of the model cloud ice particles is $r_{i}=50 \mu \mathrm{m}$.

Hydrometeor- and tracer mass mixing ratios are transported using the Walcek (2000) monotonic advection scheme instead of the third order Runge-Kutta scheme which was originally implemented in the WRF model prototype. For solving the momentum equations and the theta equation, the third order Runge-Kutta scheme is used in combination with fifth/third order spatial discretizations for horizontal/vertical advection terms. Shortwave radiation is parametrized using the Goddard shortwave scheme (Chou et al., 1998), and the RRTM scheme (Mlawer et al., 1997) is used for parametrizing longwave radiation in the simulations. Subgrid scale turbulence is parametrized applying Smagorinsky's closure scheme (e.g. Takemi and Rotunno, 2003) except in the STERAO run, where K-theory with constant horizontal $\left(K_{h}=100 \mathrm{~m}^{2} \mathrm{~s}^{-1}\right)$ and vertical $\left(K_{v}=1 \mathrm{~m}^{2} \mathrm{~s}^{-1}\right)$ coefficients is used (see discussion in Sect. 3.2.2).

For soluble trace gases the uptake by, release from, sedimentation together with, and mass transfer between different 
model categories of hydrometeors in the liquid or ice phase are calculated. Neither gas nor aqueous phase reactions are considered. Concentrations of dissolved trace gases and gases taken up by the ice phase are treated as prognostic variables (i.e. they undergo transport and parametrized turbulence). The rate of change of the gas phase concentration $C_{g}$ due to uptake/release of a tracer by/from hydrometeors is

$\left.\partial_{t} C_{g}\right|_{h y}=-\sum_{j=1}^{5}\left(\left.\partial_{t} C_{j}\right|_{m t}-\left.\partial_{t} C_{j}\right|_{e v, s u}\right)$,

where $\left.\partial_{t} C_{j}\right|_{m t}$ is the rate for the mass transfer between hydrometeors of category $j$ and the gas phase (for release $\left.\partial_{t} C_{j}\right|_{m t}<0$ ), and $\left.\partial_{t} C_{j}\right|_{e v, s u}$ is the source rate due to the evaporation or sublimation of hydrometeors of model category $j$. Here concentrations are defined as tracer mass per grid box volume. $\left.\partial_{t} C_{j}\right|_{e v, s u}$ is zero unless hydrometeors of a certain category entirely evaporate or sublimate during an integration timestep. In this case, the tracer is assumed to be completely released to the gas phase (aerosol effects, in particular sticking to the condensation nucleus are not considered). The rate of change (in addition to advection and turbulence) of the concentration $C_{j}$ of a tracer taken up by hydrometeors of model category $j$ is

$\left.\partial_{t} C_{j}\right|_{h y}=\left.\partial_{t} C_{j}\right|_{m t}+\left.\partial_{t} C_{j}\right|_{\text {sed }}+\left.\partial_{t} C_{j}\right|_{m p}-\left.\partial_{t} C_{j}\right|_{e v, s u}$,

where $\left.\partial_{t} C_{j}\right|_{\text {sed }}$ is the rate due to transport together with sedimenting hydrometeors, and $\left.\partial_{t} C_{j}\right|_{m p}$ is the rate due to mass transfer between different hydrometeor categories.

The uptake and release of trace gases are assumed to be limited by the mass transfer across the interface of the hydrometeors and by the diffusion of the trace gas in the air surrounding the meteors and is parametrized using first-order rate coefficients (Schwartz, 1986). The rate of change of the aqueous phase concentration for hydrometeor category $j$ is

$\left.\partial_{t} C_{j}\right|_{m t}=f_{j} k_{j} L_{j} C_{g}-\frac{f_{j} k_{j}}{K_{H} R T} C_{j}$,

where $f_{j}$ is the ventilation coefficient (Pruppacher and Klett, 1997), $L_{j}$ is the liquid water volume fraction of hydrometeors of category $j, K_{H}$ is the (usually temperature dependent) Henry's Law coefficient, $T$ is the temperature, and $R$ the universal gas constant, and $k_{j}$ is the first order rate coefficient (see e.g. Schwartz, 1986; Barth et al., 2001).

In the present study, the Henry's law coefficients of the soluble tracers are set to $H_{L}=1 \times 10^{6} \mathrm{~mol} \mathrm{l}^{-1} \mathrm{~atm}^{-1}$ in all sensitivity runs independent of temperature (i.e. the tracers are highly soluble and increases of $H_{L}$ with height due to decreasing temperatures are not taken into account). A preliminary sensitivity run assuming even higher Henry's law coefficients yielded very similar results, in agreement with Barth et al. (2001) and Crutzen and Lawrence (2000). In calculating the first order rate coefficients, the accommodation coefficient is set to $\alpha_{\text {acc }}=0.2$ and the molar mass of the idealized tracers used for calculating the gas phase diffusivities is set equal to the molar mass of $\mathrm{HNO}_{3}$.
Following Barth et al. (2001), the sedimentation rate is calculated using the mass weighted mean terminal velocity $\bar{u}_{\infty j}$ (positive downward) of the falling hydrometeors (all except cloud droplets, where sedimentation is neglected):

$\left.\partial_{t} C_{j}\right|_{\text {sed }}=\partial_{z}\left(\bar{u}_{\infty j} C_{j}\right)$.

The mass transfer between different hydrometeor categories is assumed to be proportional to the mass transfer of liquid or frozen water between the different categories as calculated by the microphysics parametrization:

$\left.\partial_{t} C_{j}\right|_{m p}=\sum_{k=1}^{5}\left(k_{\mathrm{ret}_{\mathrm{k}, \mathrm{j}}} R_{k, j} \frac{C_{k}}{q_{k}}-k_{\mathrm{ret}_{\mathrm{j}, \mathrm{k}}} R_{j, k} \frac{C_{j}}{q_{j}}\right)$,

where $R_{k, j}=\left.\partial_{t} q_{j}\right|_{k \rightarrow j}$ is the rate of liquid or frozen water transfer from meteors of category $k$ to meteors of category $j$ due to a microphysical process; $k_{\text {ret }}$ is a dimensionless retention fraction and is one for all processes except freezing and riming. The retention coefficient is assumed to be independent of whether wet or dry growth riming or homogeneous freezing occurs. Effects of the so-called quasi-liquid layer (e.g. Diehl et al., 1995) (of which the structure is still largely unknown) are not considered.

\section{Model setup and meteorological overview}

\subsection{Runs with large scale forcings}

In the multi-day LSF or cloud system resolving runs, socalled "large scale forcings" based on Soong and Ogura (1980) are added to the thermodynamic equation and to the equation for water vapor in order to represent the influences of larger scale dynamics which are not resolved by typical limited area cloud resolving models:

$$
\begin{aligned}
& \left(\frac{\partial \bar{\theta}}{\partial t}\right)_{L S}=-\overline{\boldsymbol{v}} \cdot \nabla \bar{\theta}-\bar{w} \frac{\partial \bar{\theta}}{\partial z} \\
& \left(\frac{\partial \bar{q}}{\partial t}\right)_{L S}=-\overline{\boldsymbol{v}} \cdot \nabla \bar{q}-\bar{w} \frac{\partial \bar{q}}{\partial z},
\end{aligned}
$$

where $\boldsymbol{v}=(u, v)$ is the horizontal wind vector, $q$ is the water vapor mixing ratio, $\theta$ is the potential temperature, and overbars denote horizontal domain averages. The large scale forcings for $q$ and $\theta$ in Eqs. (6) and (7) are derived from comprehensive observation campaigns. The gradients of $\bar{q}$ and $\bar{\theta}$, and $\bar{w}$ depend to some extent on the deep convection taking place inside the domain, which is important to note when using the traditional term "large scale forcings". In the multi-day cloud system resolving model runs, the average horizontal wind is nudged towards observed values:

$$
\left(\frac{\partial \overline{\boldsymbol{v}}}{\partial t}\right)_{L S}=-\frac{\overline{\boldsymbol{v}}-\overline{\boldsymbol{v}}_{\mathrm{obs}}}{\tau_{\mathrm{adj}}}
$$




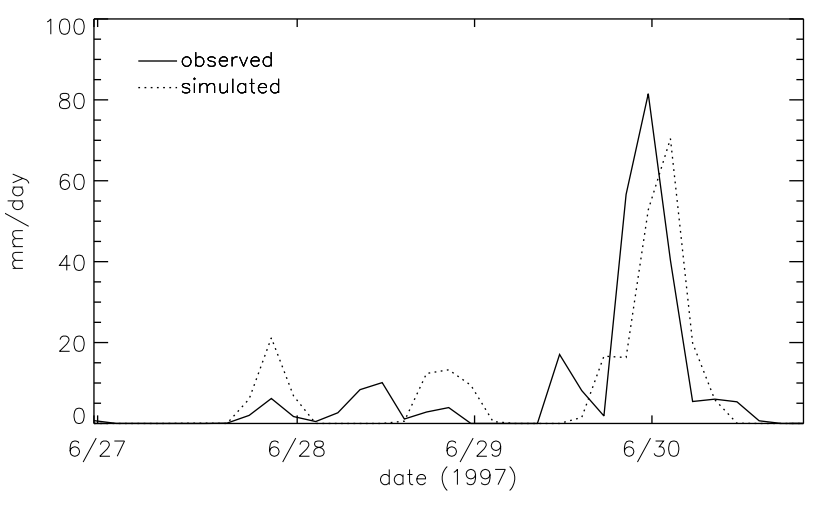

Fig. 2. Time series of modeled and observed $6 \mathrm{~h}$ average surface precipitation rates for the ARM A LSF simulation.

as in e.g. Xu and Randall (1996) with an adjustment time $\tau_{\mathrm{adj}}=1 \mathrm{~h}$. The surface skin temperatures are prescribed based on observations. In the LSF runs very small (maximum $0.1 \mathrm{~g}$ $\mathrm{kg}^{-1}$ ) water vapor perturbations are applied during the first $2.5 \mathrm{~h}$ of the simulations (prior to the onset of deep convection). The lateral boundary conditions are periodic for all variables and the tracer fields are reset to their (horizontally homogeneous) initial values every $24 \mathrm{~h}$ after an initial offset of $12 \mathrm{~h}$. Vertical large scale advection tendencies for tracers (VLSAT, Salzmann et al., 2004) are not applied. The rationale for re-initializing the tracer fields is to compensate for the lack of large scale processes and chemistry acting on the tracers and to obtain a set of results for different time slices. Re-initialization was previously applied by Lu et al. (2000) in cloud system simulations of tracer transport.

The horizontal domain size used in the 3-D LSF runs is $278 \times 278 \mathrm{~km}^{2}$ and the horizontal resolution is $2 \mathrm{~km}$. The vertical resolution is $350 \mathrm{~m}$ in the TOGA COARE runs and variable grid spacings are used in the ARM runs. The thickness of the model layers (i.e. distance between full levels) in the ARM runs increases by a factor of 1.04 in each layer from $60 \mathrm{~m}$ for the lowest layer to $350 \mathrm{~m}$ at $\sim 7261 \mathrm{~m}$ above ground level and then remains constant up to the model top at $20211 \mathrm{~m}$ above ground level. The ground level is located $360 \mathrm{~m}$ above sea level. In addition to the 3-D runs, 2-D sensitivity runs have been conducted (see Sects. 5 and 6). The horizontal domain is $500 \mathrm{~km}$ in these 2-D runs and is oriented in the east-west direction. The horizontal resolution and the vertical grid are identical to those in the corresponding 3-D simulations.

\subsubsection{The TOGA COARE run}

A seven day episode from 19-26 December 1992 at the site of the Tropical Ocean Global Atmospheres/Coupled Ocean Atmosphere Response Experiment (TOGA COARE, Webster and Lukas, 1992) Intensive Flux Array (IFA, centered at $2^{\circ} \mathrm{S}, 156^{\circ} \mathrm{E}$ in the tropical West Pacific) is modeled, which has been extensively studied using cloud system resolving models (e.g., Johnson et al., 2002; Gregory and Guichard, 2002). This episode was also studied by Salzmann et al. (2004) using the same model setup with a smaller 3-D domain and specified lateral boundary conditions for water vapor. On the whole the meteorological results from the TOGA COARE run in the present study are similar to the results presented by Salzmann et al. (2004). The precipitation rates compare well with observed data, as expected for a run in which LSF is applied, and several long-lived mesoscale convective systems develop. The water vapor bias is small (maximum $<0.7 \mathrm{~g} \mathrm{~kg}^{-1}$ ) and a cold temperature bias of about $2 \mathrm{~K}$ exists throughout the troposphere, which has also been found in similar cloud system resolving model studies of the same case.

\subsubsection{The ARM A LSF run}

The Atmospheric Radiation Measurement Program (ARM) case (ARM A, 26-30 June 1997, Southern Great Plains) is also well documented and has been studied, e.g. in an intercomparison of various cloud system resolving models $(\mathrm{Xu}$ et al., 2002). The data used for specifying the "large scale forcing" terms in the present study as well as data from observations were obtained from http://kiwi.atmos.colostate.edu/ scm/arm-data/jul97.html (Version 2 datasets, Zhang et al., 2001).

Figure 2 shows good agreement for simulated and observed $6 \mathrm{~h}$ average surface precipitation rates for the ARM A episode. The accumulated rainfall for the entire episode is $31.5 \mathrm{~mm}$ in the simulations and $32.9 \mathrm{~mm}$ in the observations. Figure $3 \mathrm{c}$ shows that the maximum rain rates coincide with the development of longer lived mesoscale systems.

The domain average simulated cloud liquid water path (excluding the first day) is $37.9 \mathrm{~g} \mathrm{~m}^{-2}$ and the average cloud ice water path (excluding the first day) is $13.7 \mathrm{~g} \mathrm{~m}^{-2}$. Both values are at the lower end, but still inside the wide range reported by Xu et al. (2002) for various other cloud system resolving models. The differences between time and horizontal domain averaged modeled and observed temperatures and water vapor mixing ratios are shown in Fig. 4. Height dependent biases of similar magnitude have also been found in other cloud system resolving studies and are not only model, but to a large extent, also case dependent. The ARM run was performed with increasing vertical grid resolution towards the Earth's surface. Increasing the resolution in the lower model layers was found to result in an earlier onset of deep convection in better agreement with the observations. Increasing the resolution in a TOGA COARE sensitivity run, on the other hand, resulted in very small changes of the modeled trace gas transport (not shown), and therefore the TOGA COARE run was performed with constant vertical resolution. 
a) STERAO

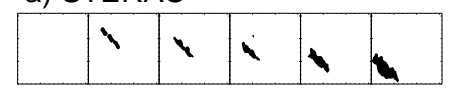

b) ARM A BUB

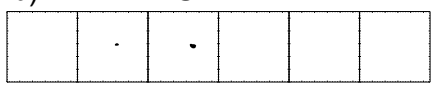

c) ARM A LSF

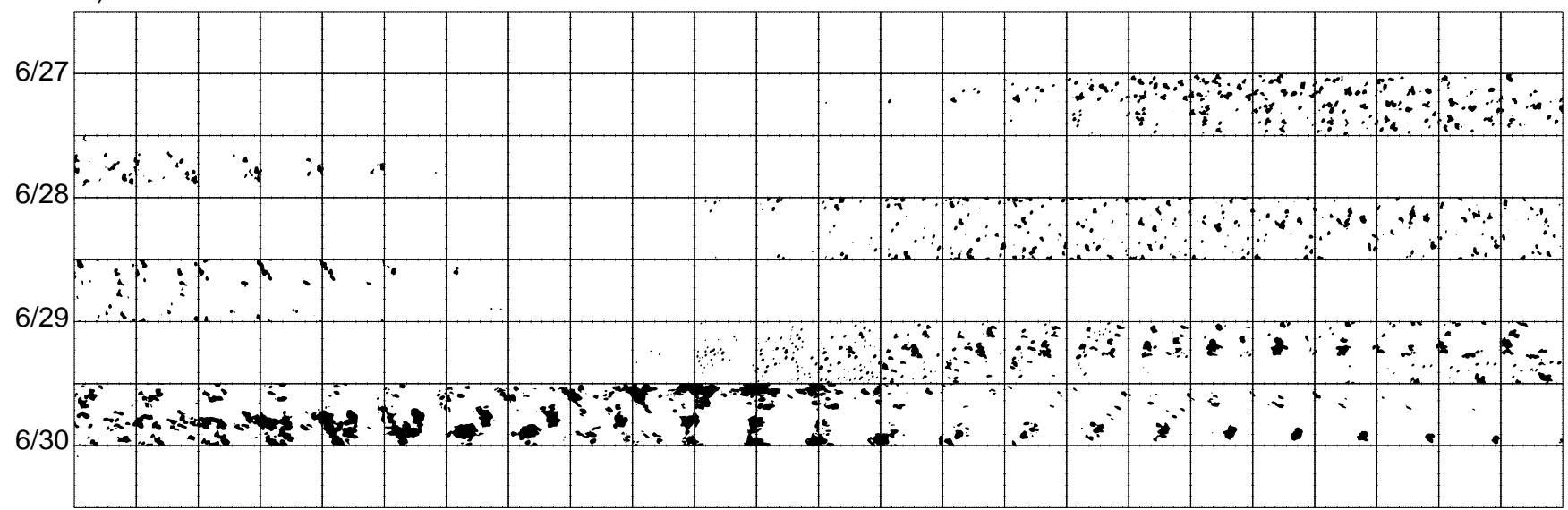

Fig. 3. Series of $X-Y$ contour plots: $1 \mathrm{~mm} \mathrm{~h}^{-1}$ filled contour of simulated rainfall rates. The interval between the individual plots is $30 \mathrm{~min}$; in $\mathbf{c}$ each row represents one half day. The $\mathrm{X}$-axes are directed in $\mathrm{W}-\mathrm{E}$ direction, and the Y-axes in S-N direction.
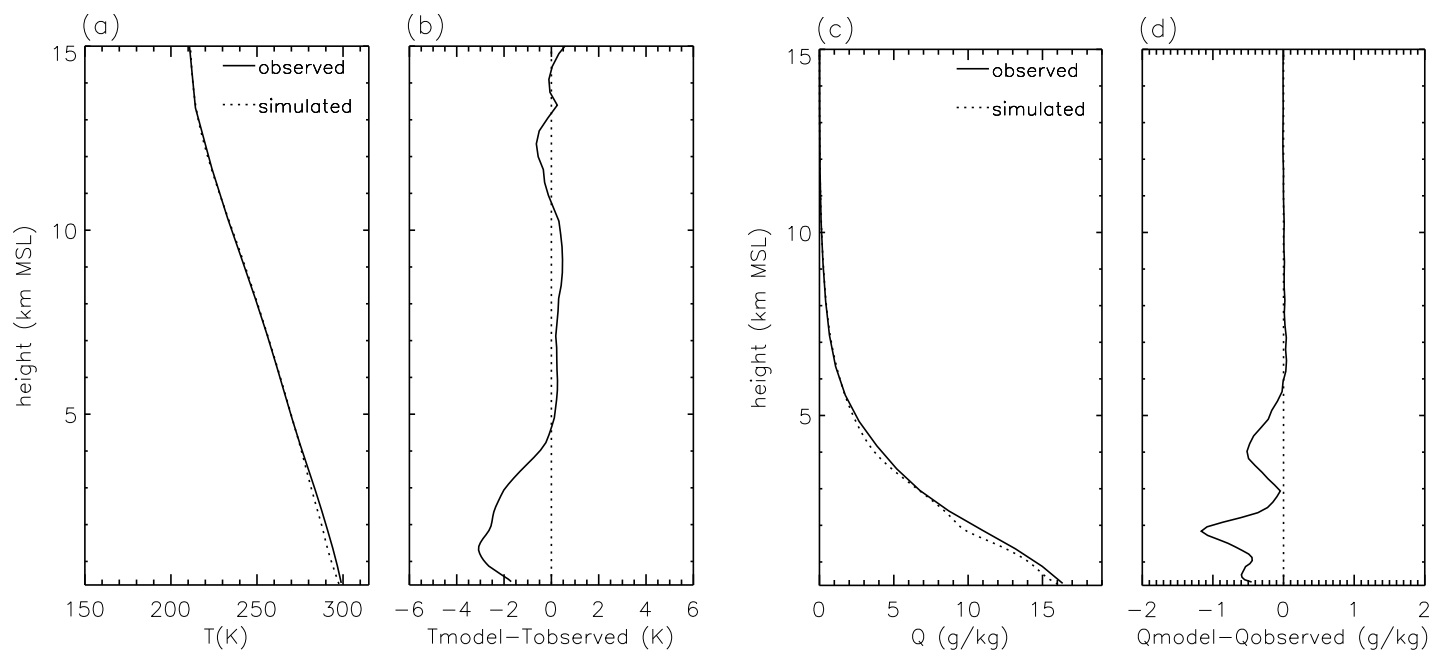

Fig. 4. Vertical profiles of modeled and observed domain and time averaged temperatures and water vapor mixing ratios for the ARM A LSF case.

3.2 Runs in which bubbles were used to initiate deep convection

\subsubsection{The ARM A BUB run}

In addition to the ARM A LSF run, a short $(2.5 \mathrm{~h})$ run was initialized on 29 June 1997, 23:30 UTC with meteorological profiles from ARM A in which a positively buoyant $\left(\Delta \theta_{\max }=5 \mathrm{~K}\right)$ thermal with radius $\mathrm{r}=20 \mathrm{~km}$ and height $\mathrm{z}_{o}=1800 \mathrm{~m}$ was used to initiate deep convection. The grid and the timestep are the same as in the ARM A LSF run. The relatively warm bubble in the ARM A bubble ("ARM A BUB") run results in a rather short lived single cell storm (Fig. 3b) with a top below $12 \mathrm{~km}$ above mean sea level (MSL), while the cloud tops in the run with large scale forcings were higher (see Sect. 5). A few sensitivity runs starting from other initial profiles based on observations during the 4-day ARM A episode yielded even shorter lived storms (not shown). If, on the other hand, large scale forcings were applied in addition to the bubble in the relatively short "ARM A 



Fig. 5. (a) and (c) Cloud ice mixing ratio contours for the STERAO case at $11350 \mathrm{~m}$ above mean sea level (MSL) after $3600 \mathrm{~s}$ and after $9000 \mathrm{~s}$ and locations of cross sections in (b) and (d); (b) and (d): Radar reflectivity (dBZ)

BUB" run, much higher cloud tops and longer lived systems developed (not shown), reflecting the importance of the large scale forcings in the ARM case. The ARM A BUB run has been designed as a sensitivity experiment in order to estimate the effects bubbles can in principle have on the transport of soluble tracers.

\subsubsection{The STERAO case}

The 10 July 1996, Stratospheric-Tropospheric Experiment: Radiation, Aerosols, and Ozone (STERAO) case has previously been studied using a cloud resolving model by Skamarock et al. (2000) and Barth et al. (2001). As in Barth et al. (2001) and Skamarock et al. (2000), this run is initialized with three positively buoyant thermals ("bubbles") with radius $\mathrm{r}=10 \mathrm{~km}$ and height $\mathrm{z}_{o}=1500 \mathrm{~m}$ and a maximum temperature perturbation at the center of $\Delta \theta_{\max }=3 \mathrm{~K}$. The model was run for $2.5 \mathrm{~h}$. The horizontal domain size used is $148 \times 148 \mathrm{~km}^{2}$ and the horizontal resolution is $2 \mathrm{~km}$. The vertical resolution is as in Barth et al. (2001) and Skamarock et al. (2000) with 50 vertical levels and grid spacings ranging from $\sim 50 \mathrm{~m}$ at the surface (at $1500 \mathrm{~m}$ above mean sea level) to $700 \mathrm{~m}$ in the upper troposphere and lower stratosphere. The timestep is $5 \mathrm{~s}$.
Figure 3a gives an impression of the evolution of the simulated storm. Radar reflectivities (e.g. Koch et al., 2005) after $3600 \mathrm{~s}$ and after $9000 \mathrm{~s}$ are shown in Fig. 5. The radar reflectivities derived from the STERAO run appear reasonable in the light of Fig. 7 of Skamarock et al. (2001), although some differences exist as one might expect in such a comparison. Some further details are discussed in Sect. 5. For numerical stability reasons, the STERAO case was run with constant eddy diffusion coefficients. In order to asses how this choice affects the results of the present study, a sensitivity run with the same eddy diffusion coefficients was performed for ARM A LSF. Using constant eddy diffusion coefficients for the ARM A LSF run did not change the results from this study significantly (not shown).

\section{Transport of highly soluble tracers}

Figure 6a shows horizontally averaged gas phase mixing ratio profiles calculated for two different initial profiles (T1 and T2) for the TOGA COARE case. The tracers with initial profiles $\mathrm{T} 1$ are initially located in the lower troposphere, while the initial profile of $\mathrm{T} 2$ is a $\mathrm{CO}$ profile which has been used by Barth et al. (2001) in their pioneering cloud resolving model study of soluble tracer transport during STERAO. The 
Table 1. Ratios $\alpha=\bar{\mu}_{s} / \bar{\mu}_{i}$, where $\bar{\mu}_{s}$ and $\overline{\mu_{i}}$ are the horizontally domain averaged mixing ratios in the upper troposphere of highly soluble and insoluble tracers, respectively, for two different initial profiles (T1 and T2) for TOGA COARE (T.C.), ARM A, and STERAO.

\begin{tabular}{lcccccccc}
\hline & T.C. $2.5 \mathrm{~h}^{2}$ & T.C. $12 \mathrm{~h}^{3}$ & T.C. $24 \mathrm{~h}^{3}$ & ARM $2.5 \mathrm{~h}^{2}$ & ARM $12 \mathrm{~h}^{3}$ & ARM $24 \mathrm{~h}^{3}$ & ARM BUB & STERAO \\
\hline$\alpha_{r}{ }^{1} \mathrm{~T} 1$ & $7.0 \times 10^{-4}$ & $2.1 \times 10^{-4}$ & $1.2 \times 10^{-4}$ & $1.1 \times 10^{-3}$ & $1.2 \times 10^{-3}$ & $1.0 \times 10^{-3}$ & $3.4 \times 10^{-2}$ & $1.8 \times 10^{-2}$ \\
$\alpha_{n r} \mathrm{~T} 1$ & $2.4 \times 10^{-2}$ & $1.0 \times 10^{-2}$ & $9.7 \times 10^{-3}$ & $7.2 \times 10^{-2}$ & $6.6 \times 10^{-2}$ & $8.4 \times 10^{-2}$ & 0.55 & 0.90 \\
& & & & & & & & \\
$\alpha_{r} \mathrm{~T} 2$ & 0.84 & 0.52 & 0.32 & 0.998 & 0.67 & 0.48 & 0.996 & 0.88 \\
$\alpha_{n r} \mathrm{~T} 2$ & 0.91 & 0.67 & 0.48 & 0.998 & 0.76 & 0.61 & 0.999 & 0.98 \\
\hline
\end{tabular}

1 Soluble tracers are either assumed to be completely retained $\left(\alpha_{r}\right)$ or completely released $\left(\alpha_{n r}\right)$.

$22.5 \mathrm{~h}$ after the onset of deep convection (defined as the first output time when the total hydrometeor mixing ratio $q_{\mathrm{totm}, \text { max }}=q_{\mathrm{cloudwater}}+$ $q_{\text {cloudice }}+q_{\text {rain }}+q_{\text {graupel }}+q_{\text {snow }}$ at a single grid point above $7 \mathrm{~km}$ exceeds $1 \mathrm{~g} \mathrm{~kg}^{-1}$ ) for each $24 \mathrm{~h}$ time slice.

3 After the beginning of each $24 \mathrm{~h}$ time slice.
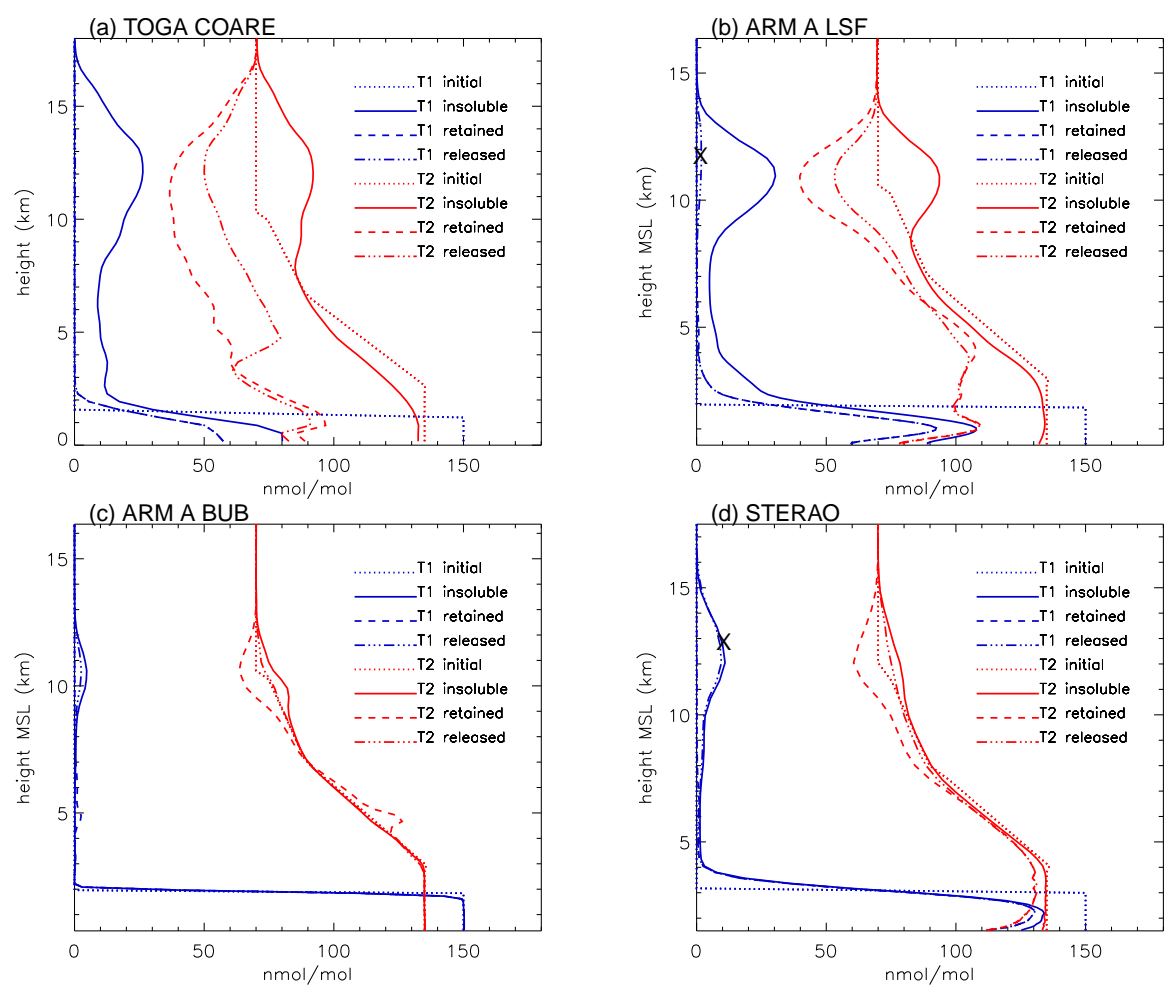

Fig. 6. Initial tracer profiles and horizontally domain averaged gas phase mixing ratios $12 \mathrm{~h}$ after the beginning of each $24 \mathrm{~h}$ time slice (a) for the TOGA COARE run (6 time slices) and (b) for the ARM A LSF run (3 time slices). (c) Initial tracer profiles and horizontally averaged mixing ratios at the end of the ARM A BUB run. For better readability (i.e. increased spacing between the individual lines) the mixing ratios in (c) were averaged over a $28 \times 30 \mathrm{~km}^{2}$ sub-domain at the western edge of the domain centered at the gridpoint $(i, j)=124,55$, where the main outflow at is located after $2.5 \mathrm{~h}$. (d) Initial tracer profiles and horizontally domain averaged mixing ratios at the end of the STERAO simulation after $2.5 \mathrm{~h}$. Note the large difference between (b) and (d) of "T1 released" in the upper troposphere in the region marked by an "X".

tracers have been assumed to be either insoluble, highly soluble and completely retained during hydrometeor freezing, or highly soluble and completely released during hydrometeor freezing. While the insoluble tracers are efficiently transported to the upper troposphere in the TOGA COARE run
(Fig. 6a), scavenging prevents efficient transport for the soluble tracers independent of the retention coefficient. This is also the case for the ARM A LSF run (Figs. 6b and 7). In Sect. 5 it will be shown that in these runs, highly soluble tracers with initial profile $\mathrm{T} 1$ are efficiently scavenged 


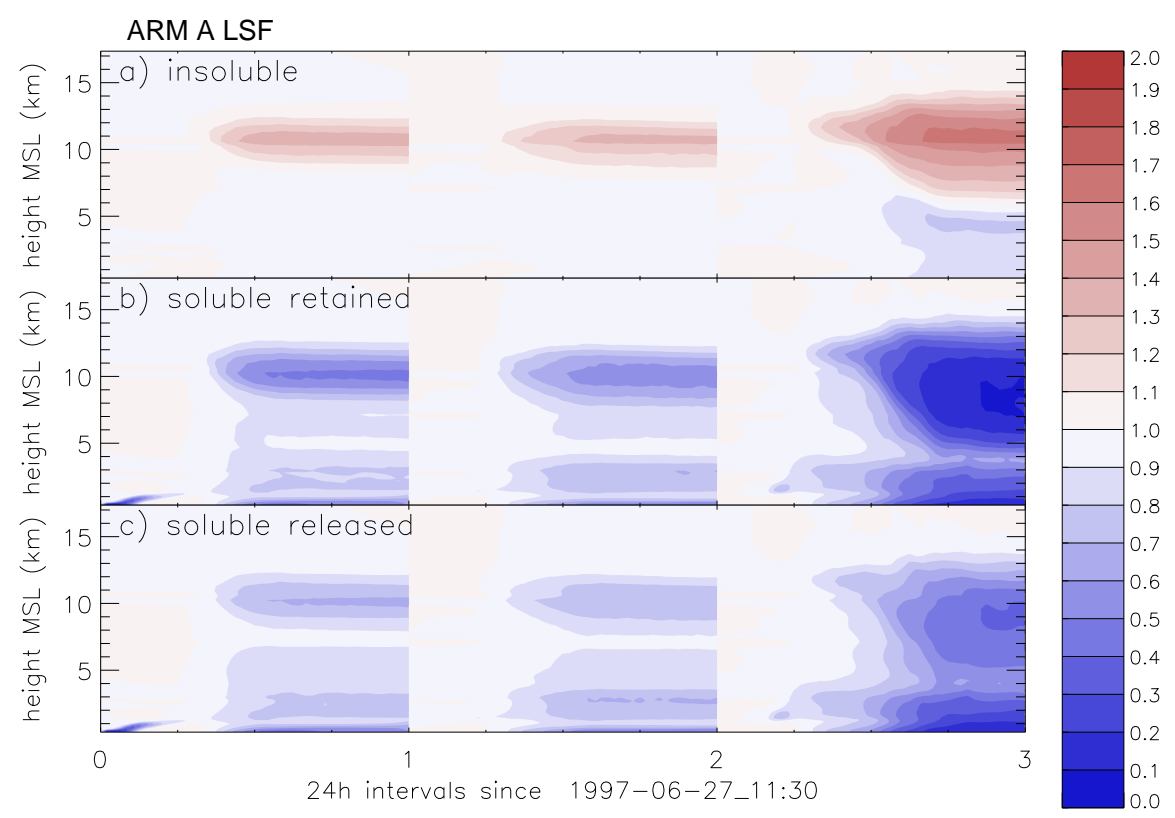

Fig. 7. Time series of the ratio $\beta$ of modeled averaged gas phase mixing ratio to initial mixing ratio for tracers with initial profile T2 during the ARM A episode (excluding the first and the last $12 \mathrm{~h}$ of the simulation). Note that $\beta$ never exceeds one if the tracer is assumed to be highly soluble.

already below the $0^{\circ} \mathrm{C}$ level. The strong sensitivity of tracers with initial profile $\mathrm{T} 2$ to the retention coefficient suggests that the retention coefficient plays a large role for the scavenging of highly soluble trace gases with a (chemical) source in the upper troposphere. In the lower troposphere, slightly higher mixing ratios of "T2 retained" compared to "T2 released" are due to more dissolved tracer being released from evaporating hydrometeors.

Based on the ratios $\alpha=\bar{\mu}_{s} / \bar{\mu}_{i}$ of soluble to insoluble tracer average mixing ratios in the upper troposphere after modeled deep convection, Barth et al. (2001) have suggested that global models such as the one used by Crutzen and Lawrence (2000) may underestimate the transport of highly soluble tracers to the upper troposphere. Crutzen and Lawrence (2000), however, investigated the transport of soluble tracers with a surface source (similar to T1), while the initial profile specified by Barth et al. (2001) is identical to T2. Figure 6 and Table 1 show that for $\mathrm{T} 1 \alpha$ is very low, in agreement with Crutzen and Lawrence (2000), who calculated mixing ratios of highly soluble tracers in the mid- and the upper troposphere to reach $5 \%$ or less of that of an insoluble tracer. For T2, on the other hand, $\alpha$ is much higher, which is in line with the result of Barth et al. (2001), who found that upper tropospheric mixing ratios of highly soluble tracers were reduced by $40-60 \%$ within a sub-domain of the STERAO simulation. (Note that especially for $\mathrm{T} 2$ the ratios generally depend on domain size, since they depend on the ratio of cloudy area to cloud free area.) Barth et al. (2001) mention a number of points why their results and the results of Crutzen and Lawrence (2000) should not be compared directly. Figure 6 and Table 1 indicate that one can attribute the large difference noted by Barth et al. (2001) primarily to the use of different initial/boundary conditions in the two studies.

Table 1 shows ratios $\alpha$ for the TOGA COARE and ARM A LSF multi-day runs based on averages over the output times $2.5 \mathrm{~h}$ after the onset of deep convection (defined as the first output time when the maximum total hydrometeor mixing ratio at a single grid point above $7 \mathrm{~km}$ exceeds $1 \mathrm{~g} \mathrm{~kg}^{-1}$ ), and also at $12 \mathrm{~h}$, and $24 \mathrm{~h}$ after each re-initialization. The upper troposphere is defined as the region of $7-16 \mathrm{~km}$ altitude for TOGA COARE, and 7-14 km above ground level for the mid-latitude cases. Furthermore, the table shows the ratios at the end of the simulation (after $2.5 \mathrm{~h}$ ) for the ARM A BUB and the STERAO case which were initialized with positively buoyant thermals as described in the previous section.

For T1 $\alpha$ is small except for $\alpha_{n r}$ in the ARM A BUB (Fig. 6c) and the STERAO case (Fig. 6d), i.e. if large scale forcings are applied together with small random perturbations, retained as well as released highly soluble tracers are not efficiently transported from the boundary layer to the upper troposphere, neither for the tropical oceanic case nor for the mid-latitude continental case, which is characterized by more vigorous deep convection. The relative difference between $\alpha_{r}$ and $\alpha_{n r}$ in Table 1 is, however, large, indicating that the retention coefficient may be important for highly soluble trace gases for which even inefficient transport could play a role. Relatively large average upper tropospheric mixing ratios of highly soluble non-retained tracers with initial profile 

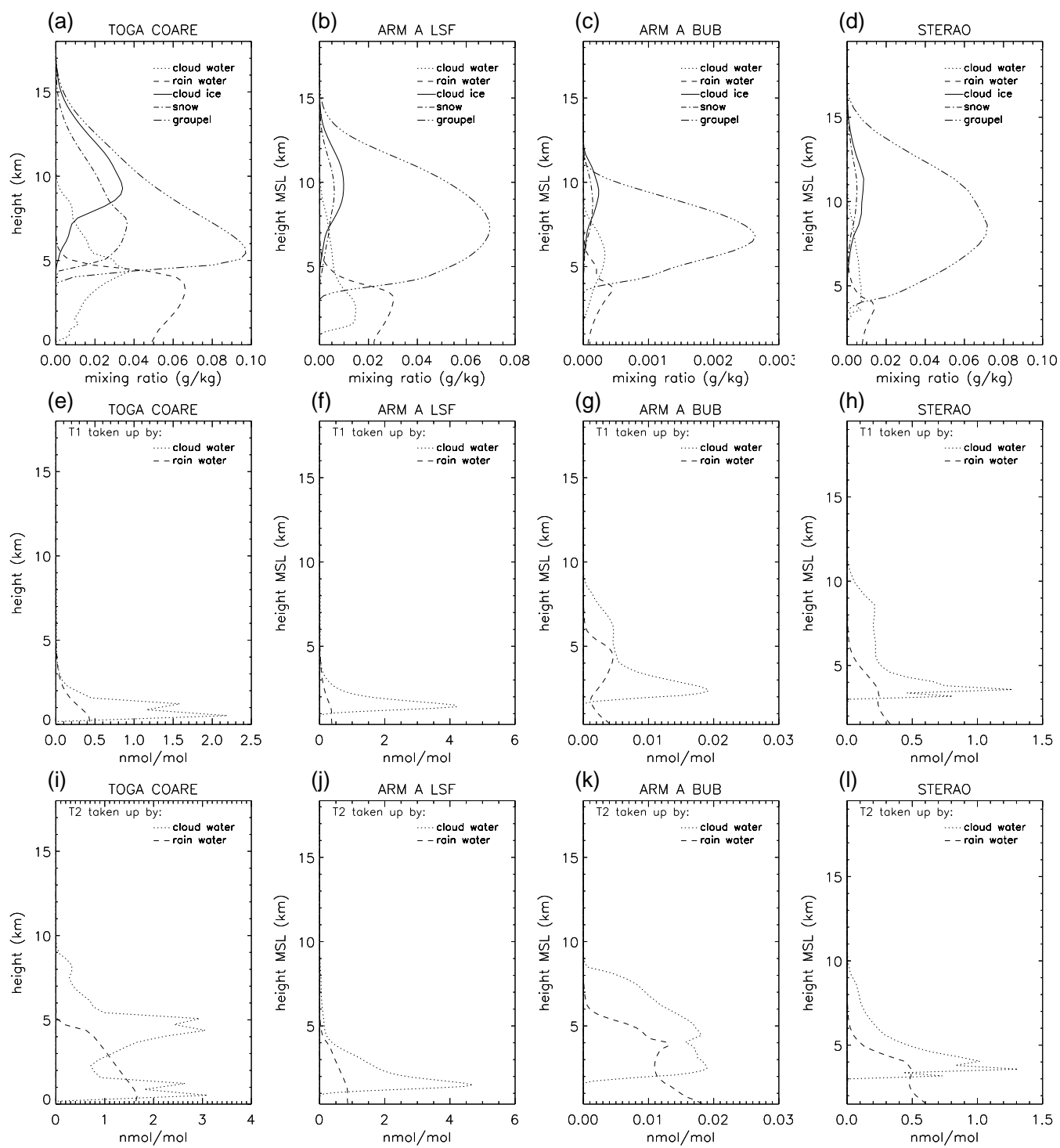

Fig. 8. Simulated time and horizontally domain averaged (a-d) hydrometeor mixing ratios and (e-h) mixing ratios (per mass of dry air) of non-retained tracer "T1 released" taken up by hydrometeors (excluding the first and the last $12 \mathrm{~h}$ for the TOGA COARE simulation and the first $18 \mathrm{~h}$ and the last $12 \mathrm{~h}$ for the ARM A LSF simulation). (i-l) Same as (e-h) for "T2 released".

T1 were only found for cases in which deep convection was initialized by bubbles (which is consistent with results from earlier studies using cloud resolving models). The reason for this apparent dependence of the results on the model setup is discussed in the next section.

\section{Influences of cloud dynamics and microphysics}

Figures $8 \mathrm{a}-\mathrm{h}$ show time and horizontally domain averaged simulated hydrometeor mixing ratios for all sensitivity runs and the mixing ratios (per mass of dry air) of the non-retained tracer T1 taken up by hydrometeors. For ARM A LSF, the first $18 \mathrm{~h}$ of the simulation (prior to the onset of deep convection) have been excluded because during this period spurious condensation occurred close to the surface. The signature of this is still visible in the lower left corner of Fig. 7. However, this does not have a significant impact on the simulated transport.

When bubbles were used to initiate deep convection, the amount of cloud water (Figs. 8c and d) and of trace gas dissolved in cloud droplets (Figs. $8 \mathrm{~g}$ and $\mathrm{h}$ ) is very low below about $2 \mathrm{~km}$. For the ARM A LSF run, on the other hand, higher cloud droplet mixing ratios tended to form in the inflow regions of the storms (e.g. "arcus clouds", marked by an "X" in Figs. 9b and c), which are not seen in the ARM 

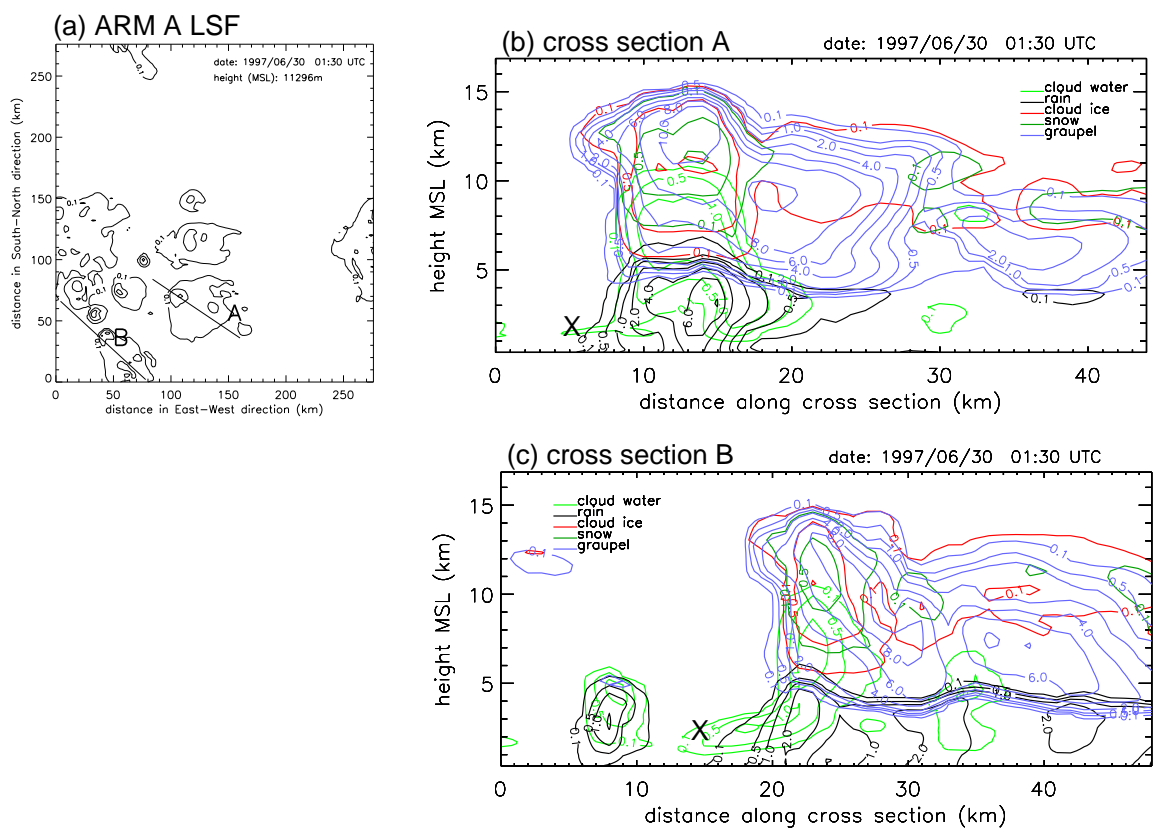

Fig. 9. (a) Cloud ice mixing ratio contours for the ARM A LSF run at about $11296 \mathrm{~m}$ above mean sea level on 30 June, 1:30 UTC and locations of cross sections in (b) and (c); (b) and (c): cross sections of hydrometeor mixing ratios with contour levels $0.1,0.5,1.0,2.0,4.0$, $6.0,8.0,10.0$. Note the high cloud water mixing ratios in the inflow region marked by an " $X$ ".

(a) ARM A BUB

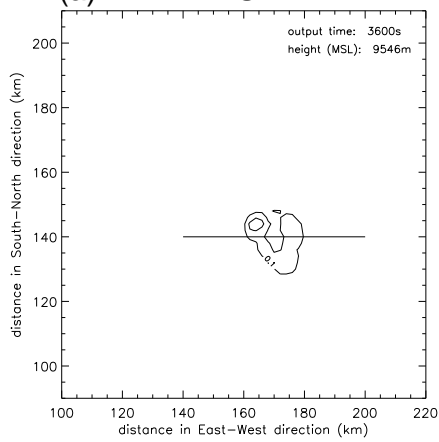

(b)

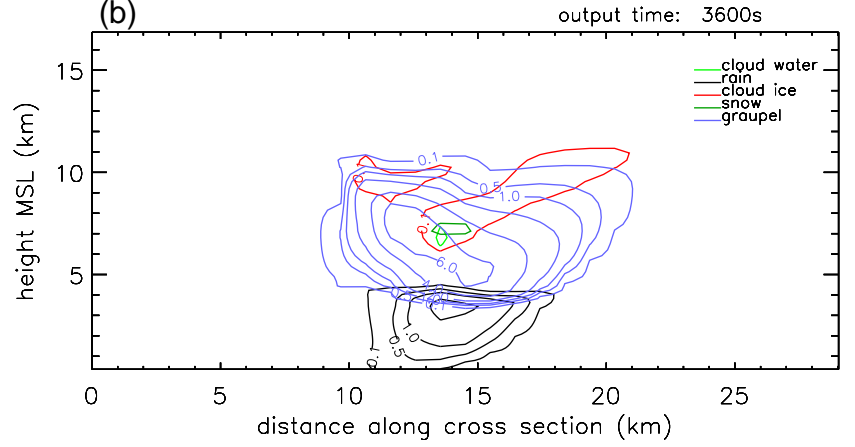

Fig. 10. (a) Cloud ice mixing ratio contours for the ARM A BUB case $9546 \mathrm{~m}$ above mean sea level after $3600 \mathrm{~s}$ and locations of cross sections in (b); (b): Contour levels as in Fig. 9b.

A BUB (Fig. 10b) run, but are simulated to also exist in the STERAO case (Fig. 11d). In the LSF runs T1 did not reach the upper troposphere once it was taken up in cloud water at low levels (Figs. 8e and f). This indicates that the different dynamics in the inflow regions are responsible for the more efficient scavenging of the non-retained tracer in the LSF runs.

Mixing ratios of the non-retained tracer $\mathrm{T} 2$ taken up by hydrometeors are shown in Fig. 8i-1. A comparison of Fig. 8i to Fig. $8 \mathrm{j}$ suggests that mid-tropospheric entrainment of $\mathrm{T} 2$ was more efficient for TOGA COARE than for ARM A LSF. This is consistent with Figs. 6a and b suggesting more efficient mid-tropospheric scavenging of T2 in the TOGA COARE run. Mid-tropospheric entrainment also enhances the mixing ratios of "T2 released" in cloud water in the ARM A BUB run (Fig. 8k) while in the STERAO case, "T2 released" in cloud water (Fig. 81) shows even lower mid-tropospheric mixing ratios than "T1 released" in cloud water (Fig. 8h) due to lower initial mixing ratios in the boundary layer (Fig. 6). The effect of mid-tropospheric scavenging is very small for 
(a) STERAO

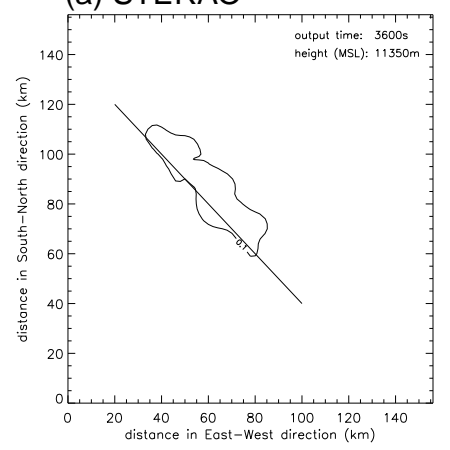

(c)

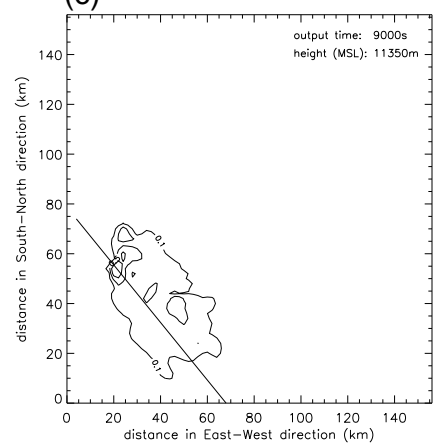

(b)

output time: 3600 s

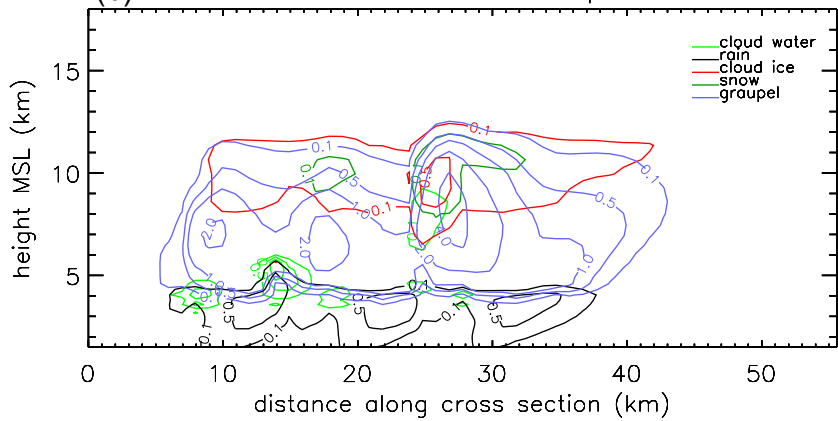

(d)

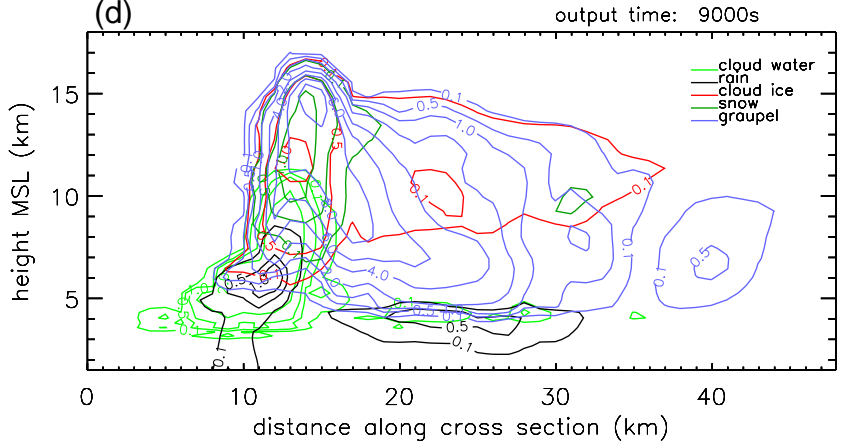

Fig. 11. (a) and (c) Same as Figs. 5a and c; (b) and (d): Contour levels as in Fig. 9b.

"T2 released" in the ARM A BUB and the STERAO run (Figs. 6c and d).

Figure 12 shows the time series of horizontally integrated production of rain water from cloud water, snow, and graupel as well as the vertical profiles of the time integrated rain water production. An overview of the microphysical processes contributing to rain water production was presented in Fig. 1. Note that a part of the rain water produced evaporates before reaching the surface. For ARM A LSF and TOGA COARE the production terms in Figs. 12a and $\mathrm{b}$ were derived from 2D model reruns (see Sect. 3.1), since the computational cost of multi-day 3-D simulations is unfortunately still relatively high. In the next section it will be shown that the results for $\mathrm{T} 1$ and T2 from the TOGA COARE 2-D runs are qualitatively similar to the corresponding results from the 3-D runs, allowing us to have some confidence in the results of these 2-D runs, at least on a qualitative basis. Detailed results from 2-D simulations of the meteorology during TOGA COARE can be found in Salzmann et al. (2004). Most rain is formed via the ice phase in all runs, but cloud water plays a much bigger role in the LSF runs than in the bubble runs (panels on the left hand side in Fig. 12). Furthermore, in the LSF runs cloud water contributes to rain formation at lower levels than in the bubble runs (panels on the right hand side in Fig. 12). Figures $9 \mathrm{~b}$ and $\mathrm{c}$ suggest that in the ARM A LSF run cloud droplets coexist with rain mainly in the inflow re- gions of the storms. Rain formation in this region is most likely a very efficient process for the scavenging of highly soluble tracers, since direct uptake of trace gases into larger rain drops is strongly limited by gas phase diffusion, in spite of ventilation being considered in Eq. (3).

The finding that more efficient scavenging of the nonretained tracer in the LSF runs appears to be associated with different microphysics and dynamics in the inflow regions differs from our initial hypothesis. Our initial hypothesis was that freezing of cloud droplets at high altitudes inside the rapidly rising bubble prior to the onset of precipitation could be responsible for the higher sensitivities to the retention coefficient in the bubble runs. However, we did not find any indication that surface precipitation sets in significantly earlier in the LSF runs when compared to the bubble runs. Time series of the grid point maximum vertical velocity (indicating the presence of strong updrafts) and of the surface precipitation for the ARM A LSF run and the ARM A BUB run are shown in Fig. 13. Despite the low temporal resolution of $30 \mathrm{~min}$, the time series indicates that surface precipitation tends to lag the formation of updrafts in the ARM A LSF as well as in the ARM A BUB run. Note also that efficient uptake of highly soluble trace gases in the cloud inflow has previously been found in the early cloud resolving model study by Wang and Chang (1993). 
(a)
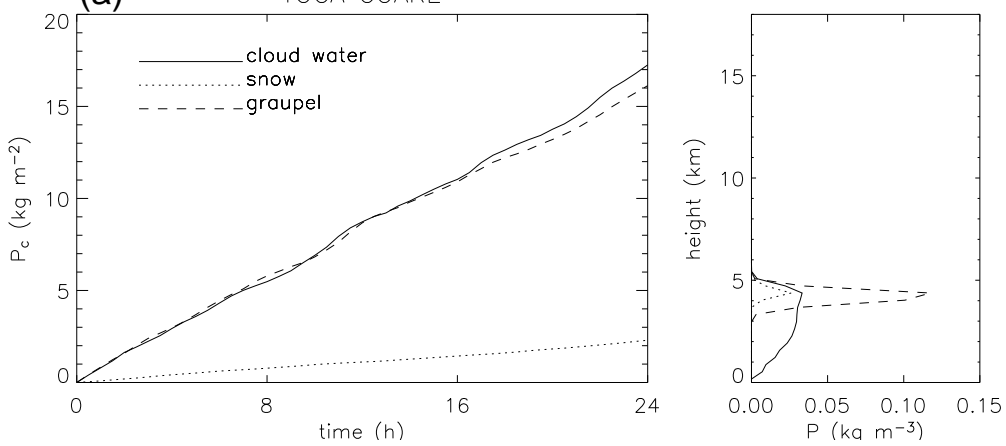

(b)
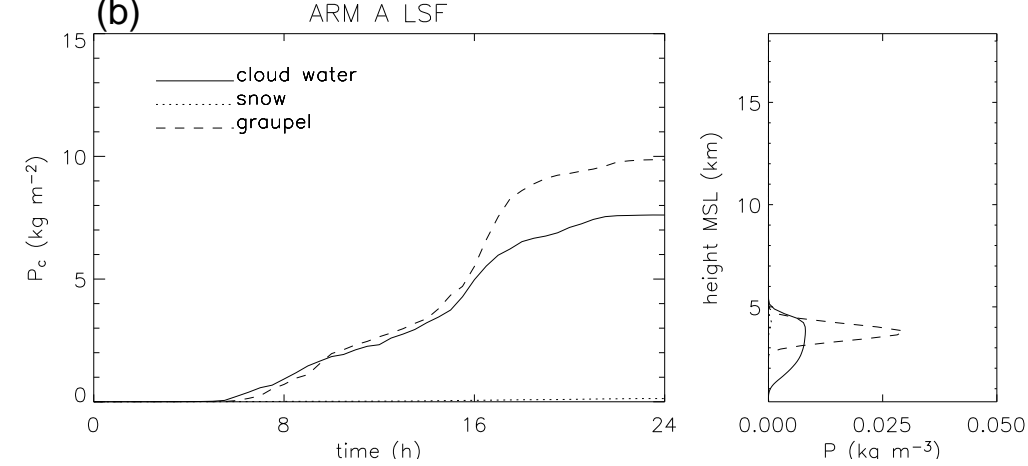

(c)

ARM A BUB
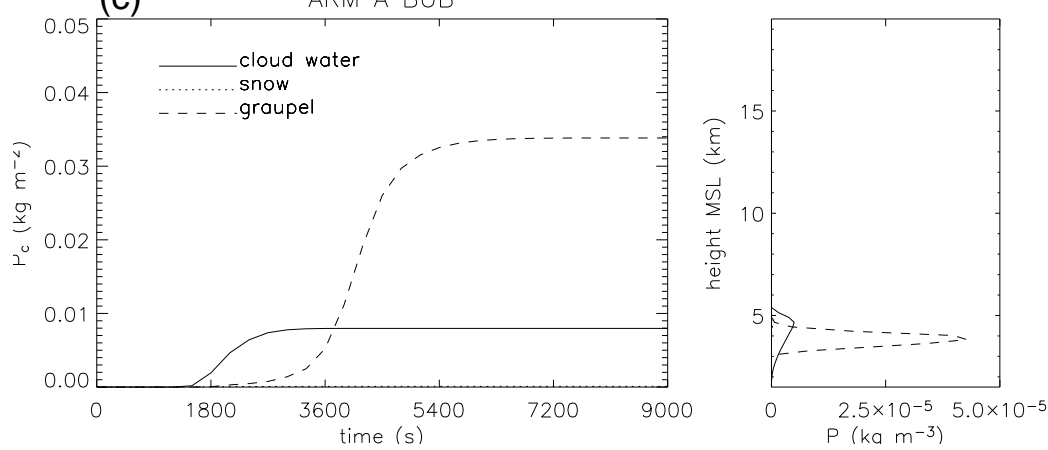

(d)

STERAO
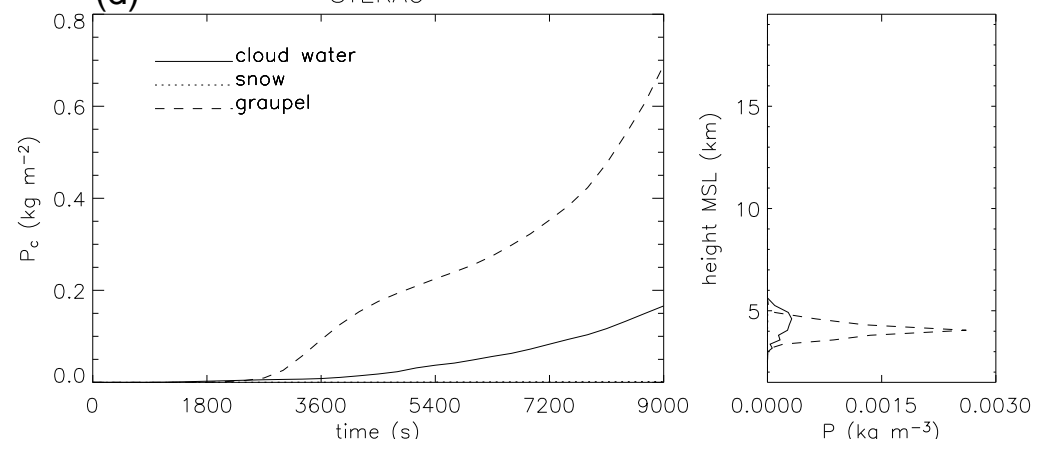

Fig. 12. Left: Time series of the horizontally integrated production of rain water from cloud water, snow, and graupel. Right: Vertical profiles of the time integrated rain water production. The values in (a) and (b) are averages over all $24 \mathrm{~h}$ slices. An overview of the microphysical processes contributing to rain water production is given in Fig. 1. 
The hydrometeor mixing ratio profiles from the ARM A BUB model run in Fig. 8 indicate that the cloud top did not reach above $12 \mathrm{~km}$. Without applying a large scale forcing in this simulation, the relatively warm bubble resulted in relatively short lived single cell storm, as previously noted. Note also that in the STERAO model run (Fig. 11), the anvil consists mostly of graupel $\left(\rho_{g}=400 \mathrm{~kg} \mathrm{~m}^{-3}\right)$. The microphysics scheme used by Barth et al. (2001), on the other hand, did not include graupel, but hail $\left(\rho_{h}=900 \mathrm{~kg} \mathrm{~m}^{-3}\right)$ as a category. In their STERAO simulations, the anvil consists mostly of snow. Their results regarding the role of the retention coefficient are, however, similar to the results from the STERAO run in this study.

\section{Additional sensitivity runs and discussion}

Mari et al. (2000) have suggested that inefficient scavenging of hydrogen peroxide $\left(\mathrm{H}_{2} \mathrm{O}_{2}\right)$ in glaciated clouds may explain the observations of enhanced $\mathrm{H}_{2} \mathrm{O}_{2}$ in outflow from tropical deep convection during TRACE-A and elsewhere (Lee et al., 1997; Jaeglé et al., 1997). T1 and T2, on the other hand, were not transported to the upper troposphere efficiently in the LSF runs, independent of whether complete release from freezing hydrometeors was assumed. However, neither T1 nor T2 is representative of typical tropical $\mathrm{H}_{2} \mathrm{O}_{2}$ profiles. $\mathrm{H}_{2} \mathrm{O}_{2}$ is photochemically produced mostly in the lower and mid-troposphere, where water vapor and $\mathrm{HO}_{\mathrm{x}}$ concentrations are higher than in the upper troposphere, mainly from the reaction of two hydroperoxy radicals:

$\mathrm{HO}_{2}+\mathrm{HO}_{2} \stackrel{\mathrm{O}_{2}, \mathrm{M}}{\longrightarrow} \mathrm{H}_{2} \mathrm{O}_{2}+\mathrm{O}_{2}$

Even in the upper troposphere, where the convective transport of methyl-hydroperoxide $\left(\mathrm{CH}_{3} \mathrm{OOH}\right)$ is an important $\mathrm{HO}_{\mathrm{x}}$ source, the chemical production of $\mathrm{H}_{2} \mathrm{O}_{2}$ can outweigh its photochemical loss, resulting in a small net photochemical production (Jaeglé et al., 2000; Salzmann, 2005). Observed tropical $\mathrm{H}_{2} \mathrm{O}_{2}$ profiles often show relatively high mixing ratios up to 5 or even $8 \mathrm{~km}$ altitude, and much lower values at the tropopause (see e.g. Heikes et al., 1996). Note that in regions far from $\mathrm{SO}_{2}$ sources, such as the TOGA COARE region, aqueous phase chemistry can be expected to play only a minor role for $\mathrm{H}_{2} \mathrm{O}_{2}$ (see Sect. 6.2 of the supplement to Tost et al., 2007). In order to investigate the transport of tracers with more " $\mathrm{H}_{2} \mathrm{O}_{2}$-like" initial profiles, a set of 2-D model runs was performed for TOGA COARE. (The cost of multiday 3-D simulations is unfortunately still relatively high as was previously noted in Sect. 5, and T1 and T2 were mainly chosen to facilitate comparisons with previous studies of idealized soluble tracer transport.) The setup of the 2-D run was previously described in Sect. 3.1.

The results for $\mathrm{T} 1$ and $\mathrm{T} 2$ in Fig.14a are qualitatively similar to the corresponding results from the 3-D runs (Fig. 6a). (Note that a detailed comparison of 3-D and 2-D runs is considered outside the scope of this paper.) Results for four

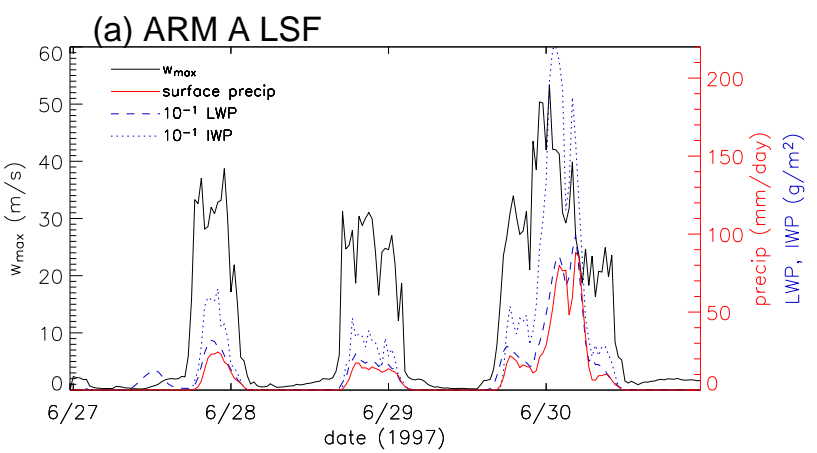

(b) ARM A BUB

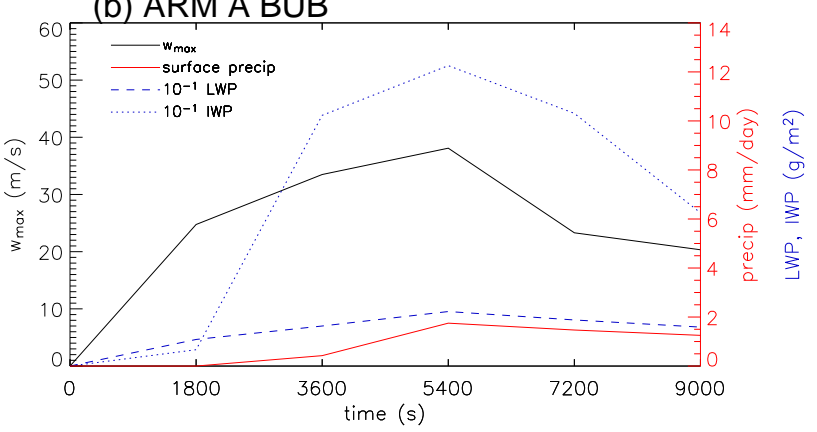

Fig. 13. Time series of domain maximum grid point vertical velocity, surface precipitation, and averaged liquid water path (LWP, includes cloud droplets and rain) and ice water path (IWP, includes cloud ice, snow, and graupel) sampled every $30 \mathrm{~min}$ for (a) ARM A LSF and (b) ARM A BUB. IWP and LWP were divided by 10 .

additional initial profiles are shown in Figs. 14b and c. T3 and $\mathrm{T} 5$ are similar to $\mathrm{T} 1$ with constant mixing ratios up to 5 and $8 \mathrm{~km}$, respectively, and zero mixing ratios above. T4 and T6 are identical to T2 below 5 and $8 \mathrm{~km}$, respectively, while above, the "background" mixing ratio was reduced significantly to $10 \mathrm{nmol} \mathrm{mol}^{-1}$. Release of "T3 released" from freezing hydrometeors in the upper troposphere is relatively inefficient. The simulated domain averaged upper tropospheric mixing ratio of "T4 released" is close to its initial value. This is a consequence of the competition between upward transport of "depleted air" (air in which the tracer mixing ratio has been depleted by scavenging) on the one hand, and release and upward transport on the other hand. For "T6 released", release and upward transport dominate, leading to significant increases of upper tropospheric mixing ratios. For "T6 retained", on the other hand, the upward transport of "depleted air" dominates. This is illustrated in Fig. 15c and $\mathrm{b}$ for a large convective system with a relatively fresh convective tower in the East, and decaying deep convection to the West. While the insoluble tracer in Fig. 15a is transported to the upper troposphere resulting in outflow beyond the $q_{\mathrm{totm}}=0.01 \mathrm{~g} \mathrm{~kg}^{-1}$ contour, "T6 retained" in Fig. $15 \mathrm{~b}$ is scavenged, and low tracer mixing ratios are found in the outflow. (Note again that uptake by ice from the gas phase is 
(a)

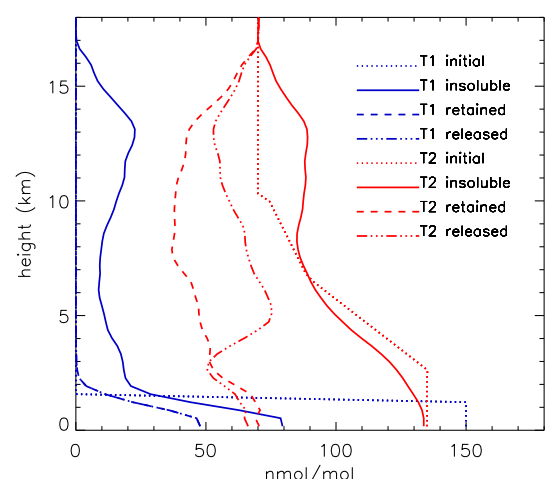

(b)

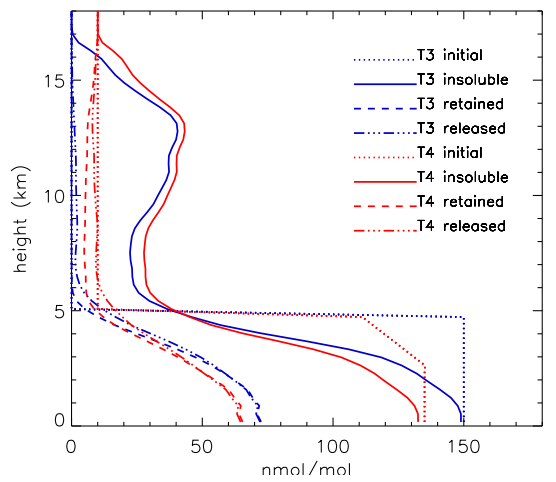

(c)

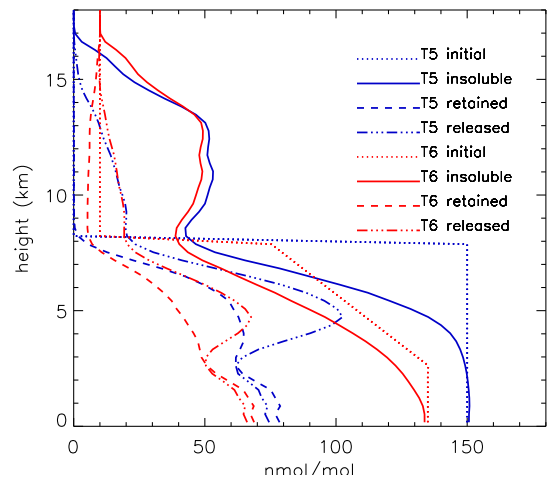

Fig. 14. (a) As Fig. 6a for the TOGA COARE 2-D run; (b) and (c) same as (a) for different initial tracer profiles.

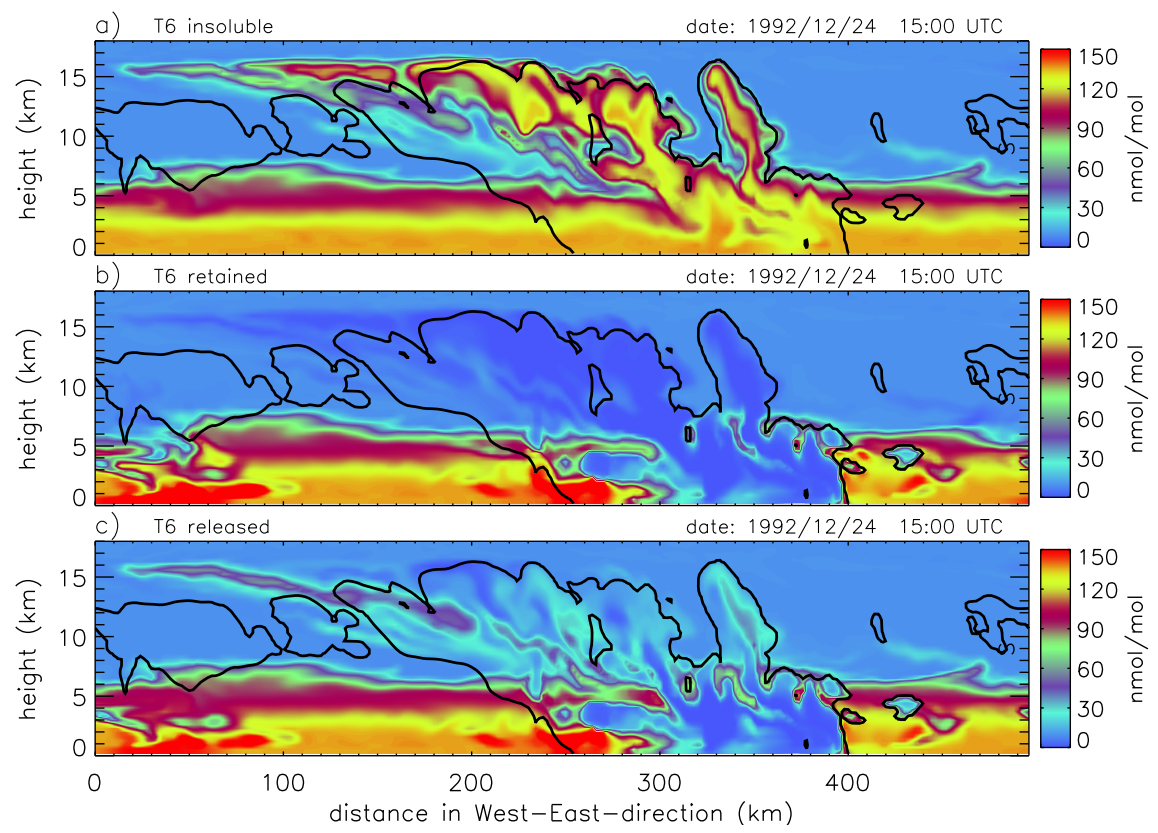

Fig. 15. Gas phase volume mixing ratio contours for tracers with initial profile T6 (a) insoluble, (b) soluble retained, (c) soluble released, and $q_{\mathrm{totm}}=0.01 \mathrm{~g} \mathrm{~kg}^{-1}$ mass mixing ratio contour from the TOGA COARE 2-D run for 24 December 1992, 15:00 UTC, where $q_{\mathrm{totm}}=$ $q_{\text {cloudwater }}+q_{\text {cloudice }}+q_{\text {rain }}+q_{\text {graupel }}+q_{\text {snow }}$.

not considered.) A considerable fraction of "T6 released" (Fig. 15c), on the other hand, is transported to the upper troposphere. However, not all storms show the same transport of "T6 released". In the western storm (at $\mathrm{x}=50-180 \mathrm{~km}$ ) in Fig. 16, "T6 released" was scavenged, while in another storm previously located to the East of this storm (also shown in Fig. 16), it was partially transported. This implies that some "competition" between different storms takes place, which plays a role for the domain averaged upper tropospheric mixing ratios.
While "T6 released" is transported to the upper troposphere in deep convection, scavenging prevents efficient transport of highly soluble tracers from below about $5 \mathrm{~km}$ (T3 and T4 in Fig 14b), where rain mixing ratios are high (Fig. 8a). This indicates that for TOGA COARE, inefficient scavenging of $\mathrm{H}_{2} \mathrm{O}_{2}$ in the glaciated part of the storms in combination with a source between 5 and $8 \mathrm{~km}$ can indeed contribute to increased observed upper tropospheric mixing ratios, supporting the hypothesis of Mari et al. (2000). 

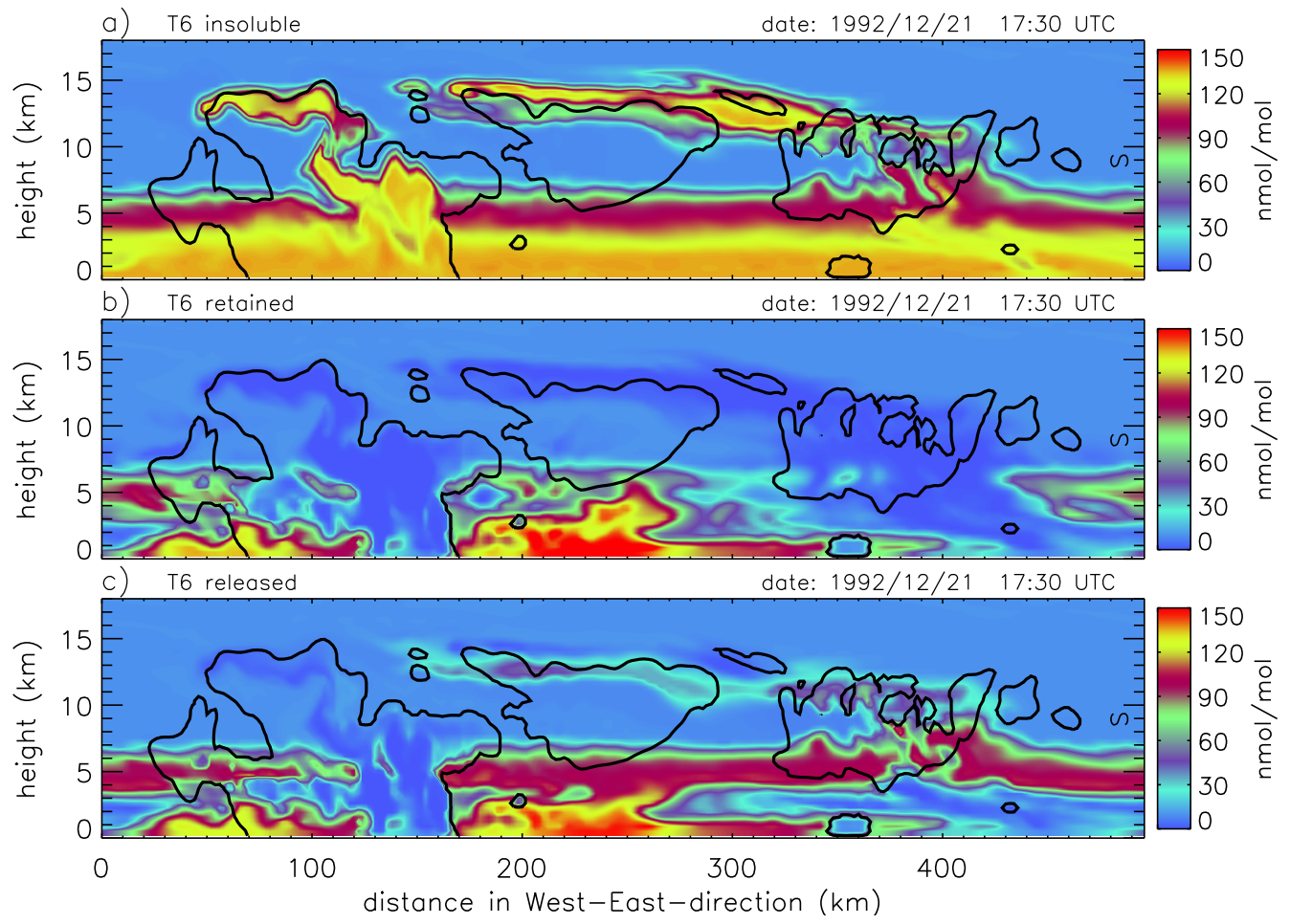

Fig. 16. Same as Fig. 15 for 21 December 1992, 17:30 UTC.

The retention coefficient for $\mathrm{H}_{2} \mathrm{O}_{2}$ is likely to depend on the details of the freezing process (Stuart and Jacobson, 2003, 2004). Strong acids such as $\mathrm{HNO}_{3}$, on the other hand, are expected to be well retained independent of freezing conditions (e.g. Voisin et al., 2000; Stuart and Jacobson, 2003). In an early laboratory study Iribarne and Pyshnov (1990) found that $\mathrm{H}_{2} \mathrm{O}_{2}$ was also completely retained in the ice phase after cloud droplet freezing. Snider et al. (1992) and Snider and Huang (1998), on the other hand, found that $\mathrm{H}_{2} \mathrm{O}_{2}$ is largely released to the gas phase during riming. Despite recent efforts by Stuart and Jacobson (2004) to explain the large range of values (from almost zero to one) from a number of laboratory studies, large uncertainty still exists regarding the retention coefficient of $\mathrm{H}_{2} \mathrm{O}_{2}$.

Further efforts to better determine retention coefficients of important trace gases for various processes and under different conditions are underway, for example within the framework of the TROPEIS (The Tropospheric Ice Phase) project, which is funded by the German Research Foundation (DFG).

The uptake of $\mathrm{H}_{2} \mathrm{O}_{2}$ onto ice directly from the gas phase was found to be small in a recent study by Clegg and Abbatt (2001), while an earlier study by Conklin et al. (1993), who studied the uptake of $\mathrm{H}_{2} \mathrm{O}_{2}$ in a flow tube packed with $200 \mu \mathrm{m}$ ice-spheres, suggested more efficient uptake (see also Meier and Hendricks, 2002). It is, however, questionable whether the laboratory data obtained for packed ice crystals is applicable to single ice crystals under upper tropospheric conditions (Meier and Hendricks, 2002). If efficient direct uptake on ice from the gas phase were considered in this study, one would expect the large sensitivity to the retention coefficient found in the "bubble" runs to decrease.

An important uncertainty (e.g. Wurzler, 1997) in the model is due to the usage of a single moment (or "bulk") microphysics scheme in which the size-distributions of rain drops, graupel, and snow are diagnosed assuming exponential (Marshall-Palmer) size distributions. Unfortunately, using size resolving microphysics schemes increases the computational cost drastically, so that such schemes have mainly been used in models with very simplified storm dynamics. Furthermore, the observational data needed for evaluating the details of various microphysics schemes under different conditions are still limited, leading to an additional uncertainty in calculations of soluble tracer transport and scavenging.

A very important question remaining is whether the results of the LSF runs are representative of most storms. Under summertime conditions, warm air bubbles are known to form over land due to differential surface heating. The rising of these bubbles can then initiate thunderstorms. Furthermore, it can not completely be ruled out that artifacts occur in the LSF runs, e.g. due to the homogeneous nudging of the $u$ and $v$ wind components, although there is no obvious reason why this should happen. 
Another potential source of artifacts in the LSF runs would be enhanced formation of cloud droplets in the inflow region due to the application of horizontally homogeneous water vapor forcings. However, condensation in the inflow regions is strongly linked to storm dynamics, i.e. convergence and lifting, and even if a notable enhancement due to horizontally homogeneous water vapor LSF occurred, it would almost certainly not be sufficient to explain why a tracer dissolved in cloud water is not transported to the upper troposphere as indicated by Figs. 8e and f.

Differences in cloud base height between different thunderstorms may, however, play a role. The thunderstorms in Colorado, where the STERAO campaign was conducted, have higher cloud bases relative to the mean sea level and a smaller region of liquid water, potentially increasing the importance of the retention coefficient for the transport of a boundary layer tracer. In addition, Colorado thunderstorms can have fairly high cloud basesabove ground. On the other hand, it is also possible that the bubbles used to initiate the model in the STERAO case may have played a role.

In Fig. 11d, the signature of the three thermals can still be seen very clearly. In the future more sophisticated setups like the one used by Stenchikov et al. (2005) and DeCaria et al. (2005), who applied horizontally non-uniform initial conditions for their simulation of a 12 July STERAO storm and took into account terrain interactions, could help to overcome these problems. Another promising option is the use of high resolution nested models or models with non-uniform horizontal grid spacings with relatively realistic land surface models. While the land surface model allows the formation of warm bubbles, nesting in principle allows the model to take into account the the influences of larger scale circulations, which are currently not resolved in limited domain cloud resolving models. Some first attempts by the authors at simulating the TOGA COARE case using multiply nested grids in the WRF model and a nudging technique for the coarsest grid provide a reason to be optimistic that nested models can be used in regions in which the large scale dynamics play an important role (in TOGA COARE especially the Hadley and Walker circulation, and the Intra-Seasonal Oscillation (e.g. Madden and Julian, 1994)).

Note that in the ARM A LSF runs the re-initialization coincides with times of minimum simulated deep convection (Fig. 2 and Fig. 3c). In the TOGA COARE runs, the six time slices yielded qualitatively similar results for the dependence of the transport of the highly soluble tracers on the retention coefficient (not shown), indicating that the results are on the whole not particularly sensitive to the time of the re-initialization.

This study has been limited to idealized tracers. The advantage of this approach is that they allow us to understand sensitivities which are difficult to investigate based on simulations of realistic trace gases. The disadvantage of idealized tracers is, however, that they are by definition not necessarily representative of realistic tracers.
The specific set of idealized tracers and bubbles for the initiation of convection in this study were partly chosen in order to obtain results comparable to previous studies regarding the role of the retention coefficient, and partly based on experience from budget analysis of sensitivity runs including photochemistry. Though these idealized tracers do not correspond exactly to any single specific tracer, artificial tracers like these have frequently been used in previous studies to provide information which is applicable to a wide range of real trace gases which have similar key qualities. More detailed discussions of this connection are found in Crutzen and Lawrence (2000).

As an initial step, this study explicitly focuses on highly soluble tracers which were found to have considerably more complicated behavior than we anticipated based on previous studies. As a future step, extending this study to moderately soluble tracers would definitely be interesting.

In order to describe reversible exchange of trace gases between the surfaces of frozen hydrometeors and the gas phase at the same time as the possible retention of trace gases due to "burial" or trapping (e.g. Kärcher and Basko, 2004; Stuart and Jacobson, 2006) in cloud resolving model simulations, it would be necessary to carry prognostic variables for both the surface and the bulk concentrations in the model. In this case, one would also have to take into account that microphysical processes occurring in association with the deep convection (see e.g. the schematic in Fig. 1) change the surface area and the ratio of surface to bulk concentration. A theoretical framework which could easily be incorporated in the microphysics parametrizations used in cloud resolving models is currently not available. Field observations of droplets freezing on an impaction grid by Snider and Huang (1998) suggested that $\mathrm{H}_{2} \mathrm{O}_{2}$ was volatilized subsequent to droplet freezing and prior to burial by continued riming.

\section{Summary and conclusions}

It was shown that different cloud droplet mixing ratios in association with different dynamics in the inflow regions can have large effects on the sensitivity of the vertical transport of highly soluble trace gases to the retention coefficient. High cloud water mixing ratios in the inflow regions were found in the cases in which LSF was applied, but not in the cases in which deep convection was initiated by bubbles. A comparison of the two ARM runs indicates that using bubbles to initiate deep convection may result in an overestimate of the influence of the retention coefficient on the vertical transport of highly soluble tracers.

In the LSF runs scavenging is found to almost entirely prevent a highly soluble tracer initially located in the lowest $1.5 \mathrm{~km}$ of the troposphere from reaching the upper troposphere, independent of the retention coefficient for both the TOGA COARE and the ARM case. 
A tracer with a high initial mixing ratio up to an altitude of $8 \mathrm{~km}$, and a low "background" above $8 \mathrm{~km}$ (T6), on the other hand, was efficiently transported to the upper troposphere if it was assumed to be completely released from hydrometeors upon freezing. This indicates that inefficient scavenging of $\mathrm{H}_{2} \mathrm{O}_{2}$ in the glaciated part of tropical storms in combination with an upper air chemical source can contribute to observed increases in its upper tropospheric mixing ratios in deep convective outflow. If complete retention was assumed for T6, the upward transport of tracer-poor air (from which the tracer has been largely scavenged) in association with downward transport of tracer-rich air lead to a decrease of the domain averaged mixing ratios of $\mathrm{T} 6$ in the upper troposphere.

For a comparable tracer with a higher "background" mixing ratio above $8 \mathrm{~km}$ (T2), the upper tropospheric mixing ratios were decreased by deep convection, independent of the retention coefficient. The magnitude of the decrease was, however, strongly dependent on the retention coefficient. This suggests that the retention coefficient plays a large role for the scavenging of highly soluble trace gases with a (chemical) source in the middle and upper troposphere. Whether release and transport on average leads to an increase of upper tropospheric mixing ratios by deep convection or whether scavenging is more important for a nonretained highly soluble tracer depends on the altitude of the (photochemical) source and on the ratio of lower and midtropospheric to upper tropospheric mixing ratios. Large differences were not only found for different initial profiles, but also between individual storms.

Given the apparent dependence of the results on the model setup (LSF vs. "bubble"), one could argue that in the future more studies with different approaches (especially with a more realistic initiation of deep convection, e.g. considering effects of orography) are needed. Such studies as well as the use of size resolved microphysics schemes without the constraint of strongly idealized storm dynamics will be facilitated by increasing computer power. For assessing potential influences of the release of $\mathrm{H}_{2} \mathrm{O}_{2}$ from freezing hydrometeors on the upper tropospheric $\mathrm{HO}_{\mathrm{x}}$ budget, additional laboratory studies are necessary in order to better determine the retention coefficient of $\mathrm{H}_{2} \mathrm{O}_{2}$ for freezing and riming processes under various conditions as well as additional in-situ observations in deep convective outflow in association with detailed model studies.

Acknowledgements. We appreciate valuable discussions on this topic with many colleagues, especially with R. von Kuhlmann, B. Bonn, and with several colleagues from the TROPEIS Collaborative Research Centre. Comments by five anonymous referees which resulted in numerous important improvements of the original manuscript are gratefully acknowledged. The work was supported by funding from the German Research Foundation (DFG) Collaborative Research Centre 641 (SFB 641) "The Tropospheric Ice Phase (TROPEIS)".

Edited by: U. Lohmann

\section{References}

Barth, M. C., Stuart, A. L., and Skamarock, W. C.: Numerical simulations of the July 10, 1996, Stratospheric-Tropospheric Experiment: Radiation, Aerosols, and Ozone (STERAO)-Deep Convection experiment storm: Redistribution of soluble tracers, J. Geophys. Res., 106, 12 381-12 400, 2001.

Chatfield, R. B. and Crutzen, P. J.: Sulfur dioxide in remote oceanic air: Cloud transport of reactive precursors, J. Geophys. Res., 89, 7111-7132, 1984.

Chou, M.-D., Suarez, M. J., Ho, C.-H., Yan, M. M.-H., and Lee, K.-T.: Parameterizations for cloud overlapping and shortwave single-scattering properties for use in general circulation and cloud ensemble models, J. Climate, 11, 202-214, 1998.

Clegg, S. M. and Abbatt, J. P. D.: Uptake of gas-phase $\mathrm{SO}_{2}$ and $\mathrm{H}_{2} \mathrm{O}_{2}$ by ice surfaces: dependence on partial pressure, temperature, and surface acidity, J. Phys. Chem. A., 105, 6630-6636, 2001.

Conklin, M. H., Sigg, A., Neftel, A., and Bales, R. C.: Atmospheresnow transfer function for $\mathrm{H}_{2} \mathrm{O}_{2}$ : Microphysical considerations, J. Geophys. Res., 98, 18 367-18376, 1993.

Crutzen, P. J. and Lawrence, M. G.: The impact of precipitation scavenging on the transport of trace gases: A 3-dimensional model sensitivity study, J. Atmos. Chem., 37, 81-112, 2000.

DeCaria, A. J., Pickering, K. E., Stenchikov, G. L., and Ott, L. E.: Lightning-generated $\mathrm{NO}_{\mathrm{x}}$ and its impact on tropospheric ozone production: A three-dimensional modeling study of a Stratosphere-Troposphere Experiment: Radiation, Aerosols and Ozone (STERAO-A) thunderstorm, J. Geophys. Res., 110, D14303, doi:10.1029/2004JD005556, 2005.

Dickerson, R. R., Huffman, G. J., Luke, W. T., Nunnermacker, L. J., Pickering, K. E., Leslie, A. C. D., Lindsey, C. G., Slinn, W. G. N., Kelly, T. J., Daum, P. H., Delaney, A. C., Greenberg, J. P., Zimmerman, P. R., Boatman, J. F., Ray, J. D., and Stedman, D. H.: Thunderstorms: An important mechanism in the transport of air pollutants, Science, 235, 460-465, 1987.

Diehl, K., Mitra, S. K., and Pruppacher, H. R.: A laboratory study of the uptake of $\mathrm{HNO}_{3}$ and $\mathrm{HCl}$ vapor by snow crystals and ice spheres at temperatures between 0 and $-40^{\circ} \mathrm{C}$, Atmos. Environ., 29, 975-981, 1995.

Gregory, D. and Guichard, F.: Aspects of the parametrization of organized convection: Contrasting cloud resolving model and single-column model realizations, Quart. J. Roy. Meteorol. Soc., 128, 625-646, 2002.

Hales, J. M. and Dana, M. T.: Precipitation scavenging of urban pollutants by convective storm systems, J. Appl. Meteorol., 18, 294-316, 1979.

Heikes, B., Lee, M., Jacob, D., Talbot, R., Bradshaw, J., Singh, H., Blake, D., Anderson, B., Fuelberg, H., and Thompson, A. M.: Ozone, hydroperoxides, oxides of nitrogen, and hydrocarbon budgets in the marine boundary layer over the South Atlantic, J. Geophys. Res., 101, 24 221-24 234, 1996.

Iribarne, J. V. and Pyshnov, T.: The effect of freezing on the composition of supercooled droplets - I. Retention of $\mathrm{HCl}, \mathrm{HNO}_{3}$, $\mathrm{NH}_{3}$, and $\mathrm{H}_{2} \mathrm{O}_{2}$, Atmos. Environ., 24A, 383-387, 1990.

Isaac, G. A. and Joe, P. I.: The vertical transport and redistribution of pollutants by clouds, in: The Meteorology of Acid Deposition, edited by: Samson, P. J., Air Pollution Control Association, Pittsburgh, PA, U.S.A., 496-512, 1983.

Jaeglé, L., Jacob, D. J., Wennberg, P. O., Spivakovsky, C. M., 
Hanisco, T. F., Lanzendorf, E. J., Hinsta, E. J., Fahey, D. W., Keim, E. R., Proffit, M. H., Atlas, E. L., Flocke, F., Schauffer, S., McElroy, C. T., Midwinter, C., Pfister, L., and Wilson, J. C.: Observed $\mathrm{OH}$ and $\mathrm{HO}_{2}$ in the upper troposphere suggest a major source from convective injection of peroxides, Geophys. Res. Lett., 24, 3181-3184, 1997.

Jaeglé, L., Jacob, D. J., Brune, W. H., Faloona, I., Tan, D., Heikes, B. G., Kondo, Y., Sachse, G. W., Anderson, B., Greogory, G. L., Singh, H. B., Pueschel, R., Ferry, G., Blake, D. R., and Shetter, R. E.: Photochemistry of $\mathrm{HO}_{\mathrm{x}}$ in the upper troposphere at northern midlatitudes, J. Geophys. Res., 105, 3877-3892, 2000.

Johnson, D. E., Tao, W.-K., Simpson, J., and Sui, C.-H.: A study of the response of deep tropical clouds to large-scale thermodynamic forcings. Part I: Modeling strategies and simulations of TOGA COARE convective systems, J. Atmos. Sci., 59, 34923518, 2002.

Kärcher, B. and Basko, M. M.: Trapping of trace gases in growing ice crystals, J. Geophys. Res., 109, D22 204, doi:10.1029/2004JD005254, 2004.

Koch, S. E., Ferrier, B., Stoelinga, M. T., Szoke, E., Weiss, S. J., and Kain, J. S.: The use of simulated radar reflectivity fields in the diagnosis of mesoscale phenomena from high-resolution WRF model forecasts, in: 32nd Conf. on Radar Meteorology, p. J4J.7, Amer. Meteorol. Soc., Albuquerque, NM, 2005.

Krueger, S. K., Fu, Q., Liou, K. N., and Chin, H.-N. S.: Improvements of an ice-phase microphysics parameterization for use in numerical simulations of tropical convection, J. Appl. Meteorol., 34, 281-287, 1995.

Lee, M., Heikes, B. G., Jacob, D. J., and Sachse, G., and Anderson, B.: Hydrogen peroxide, organic hydroperoxide, and formaldehyde as primary pollutants from biomass burning, J. Geophys. Res., 102, 1301-1309, 1997.

Lin, Y.-L., Farley, R. D., and Orville, H. D.: Bulk parameterization of the snow field in a cloud model, J. Clim. Appl. Meteorol., 22, 1065-1092, 1983.

Lord, S. J., Willoughby, H. E., and Piotrowicz, J. M.: Role of a parameterized ice-phase microphysics in an axisymmetric, nonhydrostatic tropical cyclone model, J. Atmos. Sci., 41, 2836-2848, 1984.

Lu, R., Lin, C., Turco, R., and Arakawa, A.: Cumulus transport of chemical tracers. 1. Cloud-resolving model simulations, J. Geophys. Res., 105, 10001-10221, 2000.

Madden, R. A. and Julian, P. R.: Observations of the 40-50 day tropical oscillation - A review, Mon. Weather Rev., 122, 814837, 1994.

Mari, C., Jacob, D. J., and Bechtold, P.: Transport and scavenging of soluble gases in a deep convective cloud, J. Geophys. Res., 105, 22 255-22 267, 2000.

Meier, A. and Hendricks, J.: Model studies on the sensitivity of upper tropospheric chemistry to heterogeneous uptake of $\mathrm{HNO}_{3}$ on cirrus ice particles, J. Geophys. Res., 107, 4696, doi:10.1029/2001JD000735, 2002.

Mlawer, E. J., Taubman, S. J., Brown, P. D., Iacono, M. J., and Clough, S. A.: Radiative transfer for inhomogeneous atmosphere: RRTM, a validated correlated-k model for the longwave, J. Geophys. Res., 102, 16 663-16 682, 1997.

Prather, M. J. and Jacob, D. J.: A persistent imbalance in $\mathrm{HO}_{\mathrm{x}}$ and $\mathrm{NO}_{\mathrm{x}}$ photochemistry of the upper troposphere driven by deep tropical convection, Geophys. Res. Lett., 24, 3189-3192, 1997.
Pruppacher, H. R. and Klett, J. D.: Microphysics of clouds and precipitation, Kluwer, Dordrecht, 1997.

Salzmann, M.: Influences of deep convective cloud systems on tropospheric trace gases and photochemistry over the tropical West Pacific: A modeling case study, Ph.D. thesis, Johannes Gutenberg-Universität Mainz, Mainz, Germany,http://nbn-resolving.de/urn/resolver.pl?urn=urn:nbn:de: hebis:77-9470, 2005.

Salzmann, M., Lawrence, M. G., Phillips, V. T. J., and Donner, L. J.: Modelling tracer transport by a cumulus ensemble: Lateral boundary conditions and large-scale ascent, Atmos. Chem. Phys., 4, 1797-1811, 2004,

http://www.atmos-chem-phys.net/4/1797/2004/.

Schwartz, S. E.: Mass-transport considerations pertinent to aqueous phase reactions of gases in liquid-water clouds, Pages 415-471 of: Chemistry of Multiphase Atmospheric Systems, edited by: Jaeschke, W., Springer-Verlag, Berlin and Heidelberg, Germany, 1986.

Skamarock, W. C., Klemp, J. B., and Dudhia, J.: Prototypes for the WRF (Weather Research and Forecasting) model, in: Preprints, Ninth Conf. Mesoscale Processes, J11-J15, Amer. Meteorol. Soc., Fort Lauderdale, FL, 2001.

Skamarock, W. C., Powers, J. G., Barth, M., Dye, J. E., Matejka, T., Bartels, D., Baumann, K., Stith, J., Parrish, D. D., and Hubler, G.: Numerical simulations of the July 10 StratosphericTropospheric Experiment: Radiation, Aerosols, and Ozone/Deep Convection Experiment convective system: Kinematics and transport, J. Geophys. Res., 105, 19973-19 990, 2000.

Snider, J. R. and Huang, J.: Factors influencing the retention of hydrogen peroxide and molecular oxygen in rime ice, J. Geophys. Res., 103, 1405-1415, 1998.

Snider, J. R., Montague, D. C., and Vali, G.: Hydrogen peroxide retention in rime ice, J. Geophys. Res., 97, 7569-7578, 1992.

Soong, S.-T. and Ogura, Y.: Response of tradewind cumuli to largescale processes, J. Atmos. Sci., 37, 2035-2050, 1980.

Stenchikov, G., Pickering, K., DeCaria, A., Tao, W.-K., Scala, J., Ott, L., Bartels, D., and Matejka, T.: Simulation of the fine structure of the 12 July 1996 Stratosphere-Troposphere Experiment: Radiation, Aerosols and Ozone (STERAO-A) storm accounting for the effects of terrain and interaction with mesoscale flow, J. Geophys. Res., 110, D14304, doi:10.1029/2004JD005582, 2005.

Stuart, A. L. and Jacobson, M. Z.: A timescale investigation of volatile chemical retention during hydrometeor freezing: Nonrime freezing and dry growth riming without spreading, J. Geophys. Res., 108, 4178, doi:10.1029/2001JD001408, 2003.

Stuart, A. L. and Jacobson, M. Z.: Chemical retention during dry growth riming, J. Geophys. Res., 109, D07305, doi:10.1029/2003JD004197, 2004.

Stuart, A. L. and Jacobson, M. Z.: A numerical model of the partitioning of trace chemical solutes during drop freezing, J. Atmos. Chem., 53, 13-42, 2006.

Takemi, T. and Rotunno, R.: The effects of subgrid model mixing and numerical filtering in simulations of mesoscale cloud systems, Mon. Wea. Rev., 131, 2085-2191, 2003.

Tost, H., Jöckel, P., Kerkweg, A., Pozzer, A., Sander, R., and Lelieveld, J.: Global cloud and precipitation chemistry and wet deposition: tropospheric model simulations with ECHAM5/MESSy1, Atmos. Chem. Phys. Discuss., 7, 785-848, 2007 , 
http://www.atmos-chem-phys-discuss.net/7/785/2007/.

Voisin, D., Legrand, M., and Chaumerliac, N.: Scavenging of acidic gases $\left(\mathrm{HCOOH}, \mathrm{CH}_{3} \mathrm{COOH}, \mathrm{HNO}_{3}, \mathrm{HCl}\right.$, and $\left.\mathrm{SO}_{2}\right)$ and ammonia in mixed liquid-solid water clouds at the Puy de Dôme mountain (France), J. Geophys. Res., 105, 6817-6836, 2000.

Walcek, C. J.: Minor flux adjustment near mixing ratio extremes for simplified yet highly accurate monotonic calculation of tracer advection, J. Geophys. Res., 105, 9335-9348, 2000.

Wang, C. and Chang, J. S.: A three-dimensional numerical model of cloud dynamics, microphysics, and chemistry: 3. Redistribution of pollutants, J. Geophys. Res., 98, 16787-16798, 1993.

Wang, C. and Crutzen, P. J.: Impact of a simulated severe local storm on the redistribution of sulfur dioxide, J. Geophys. Res., 100, 11357-11368, 1995.

Webster, P. J. and Lukas, R.: TOGA COARE: The Coupled OceanAtmosphere Response Experiment, Bull. Am. Meteorol. Soc., 73, 1377-1416, 1992.

Wicker, L. J. and Skamarock, W. C.: Time-splitting methods for elastic models using forward time schemes, Mon. Wea. Rev., 130, 2088-2097, 2002.
Wurzler, S.: The scavenging of nitrogen compounds by clouds and precipitation: Part II. The effects of cloud microphysical parameterization on model predictions of nitric acid scavenging by clouds, Atmos. Res.,47-48, 219-233, 1997.

Xu, K.-M. and Randall, D. A.: Explicit simulation of cumulus ensembles with GATE phase III data: Comparison with observations, J. Atmos. Sci., 53, 3710-3736, 1996.

Xu, K.-M., Cederwall, R. T., Donner, L. J., Grabowski, W. W., Guichard, F., Johnson, D. E., Khairoudtdinov, M., Krueger, S. K., Petch, J. C., Randall, D. A., Seman, C. J., Tao, W.-K., Wang, D., Xie, S. C., Yio, J. J., and Zhang, M.-H.: An intercomparison of cloud-resolving models with the Atmospheric Radiation Measurement summer 1997 Intensive Observation Period data, Quart. J. Roy. Meteorol. Soc., 128, 593-624, 2002.

Yin, Y., Carslaw, K. S., and Parker, D. J.: Redistribution of trace gases by convective clouds - mixed phase processes, Atmos. Chem. Phys., 2, 293-306, 2002, http://www.atmos-chem-phys.net/2/293/2002/.

Zhang, M. H., Lin, J. L., Cederwall, R. T., Yio, J. J., and Xie, S. C.: Objective analysis of ARM IOP data: Method and sensitivity, Mon. Wea. Rev., 129, 295-311, 2001. 